\title{
Calcium-dependent cytosolic phospholipase A2 activation is implicated in neuroinflammation and oxidative stress associated with ApoE4
}

Shaowei Wang

USC: University of Southern California

Boyang Li

University of Southern California

Victoria Solomon

University of Southern California

Alfred Fonteh

Huntington Medical Research Institutes

Stanley I. Rapoport

NIAAA: National Institute on Alcohol Abuse and Alcoholism

\section{David A. Bennett}

Rush University Medical Center

\section{Zoe Arvanitakis}

Rush University Medical Center

Helena C. Chui

USC: University of Southern California

Carol A. Miller

USC: University of Southern California

Patrick M. Sullivan

Duke University

Hoau-Yan Wang

CUNY: City University of New York

Hussein Yassine ( $\nabla$ hyassine@usc.edu )

University of Southern California https://orcid.org/0000-0002-2483-649X

Research article

Keywords: cPLA2, ApoE4, Alzheimer's disease, p38 MAPK, neuroinflammation, Oxidative stress

Posted Date: February 12th, 2021

DOI: https://doi.org/10.21203/rs.3.rs-68804/v3 
License: (c) (i) This work is licensed under a Creative Commons Attribution 4.0 International License. Read Full License

Version of Record: A version of this preprint was published at Molecular Neurodegeneration on April 16th, 2021. See the published version at https://doi.org/10.1186/s13024-021-00438-3. 


\section{Abstract}

Background: Apolipoprotein E4 (APOE4) is associated with a greater response to neuroinflammation and the risk of developing late-onset Alzheimer's disease (AD), but the mechanisms for this association are not clear. The activation of calcium-dependent cytosolic phospholipase A2 (CPLA2) is involved in inflammatory signaling and is elevated within the plaques of $A D$ brains. The relation between APOE4 genotype and CPLA2 activity is not known.

Methods: Mouse primary astrocytes, mouse and human brain samples differing by $A P O E$ genotypes were collected for measuring cPLA2 expression, phosphorylation, and activity in relation to measures of inflammation and oxidative stress.

Results: Greater CPLA2 phosphorylation, CPLA2 activity and leukotriene B4 (LTB4) levels were identified in ApoE4 compared to ApoE3 in primary astrocytes, brains of ApoE-targeted replacement (ApoE-TR) mice, and in human brain homogenates from the inferior frontal cortex of patients with $A D$ carrying $A P O E 3 / 4$ compared to $A P O E 3 / 3$. Greater CPLA2 phosphorylation was also observed in human postmortem frontal cortical synaptosomes and primary astrocytes after treatment with recombinant ApoE4 ex vivo. In ApoE4 astrocytes, the greater levels of LTB4, reactive oxygen species (ROS), and inducible nitric oxide synthase (iNOS) were reduced after CPLA2 inhibition.

Conclusions: Our findings implicate greater activation of CPLA2 signaling system with APOE4, which could represent a potential drug target for mitigating the increased neuroinflammation with APOE4 and AD.

\section{Background}

The enzyme phospholipase A2 (PLA2) catalyzes the hydrolysis of the stereospecifically numbered $(s n-2)$ ester bond of substrate phospholipids in the cell membrane to produce a free fatty acid and a lysophospholipid [1]. Calcium-independent PLA2 (iPLA2) has a greater affinity for releasing docosahexaenoic acid (DHA, 22:6 n-3), which acts as a signaling molecule during neurotransmission and as the precursor of anti-inflammatory and antioxidant resolvins [2,3]. Calcium-dependent cytosolic phospholipase A2 (CPLA2) releases arachidonic acid (AA, 20:4 n-6), which plays important functions in storing energy, as a second messenger in neurotransmission, and as the precursor of eicosanoids $[4,5]$. Free AA can be oxidized by cyclooxygenase (COX) or lipoxygenase (LOX) to produce prostaglandins or leukotrienes, which are potent mediators of inflammation $[1,6]$. In astrocytes, CPLA2 interacts with mitochondrial antiviral-signaling protein (MAVS) to boost nuclear factor kappa-light-chain-enhancer of activated B cell (NF-kB)-driven inflammatory responses [7]. In microglia, CPLA2 and AA metabolic pathways contribute to reactive oxygen species (ROS) and nitric oxide (NO) production during cell activation[8]. cPLA2 activity depends on its phosphorylation, regulated by mitogen-activated protein kinase (MAPK) pathways $[9,10]$. 
A lower amount of Ab oligomers and the absence of glial activation markers in both astrocytes and microglia distinguish the brains of individuals with greater brain $\mathrm{Ab}$ plaques and tangles but resilience to AD dementia from those with dementia [11]. CPLA2 activation is one of the pathways that activates microglia and astrocytes in the brain. The CPLA2 gene, protein levels, and phosphorylated form are increased around AD brains' plaques compared to healthy controls [12-14]. Increased activation of CPLA2 is observed in the hippocampus of human amyloid precursor protein (hAPP) transgenic mice [14]. The activation of CPLA2 by Ab oligomers contributes to dysregulation of fatty acid metabolism and promotes neurodegeneration $[15,16]$. Overexpression of p25 (Protein 25, a cyclin-dependent kinase 5 activator) in neurons increases the expression of CPLA2, leading to lysophosphatidylcholine (LPC) secretion and the activation of astrocytes and production of proinflammatory cytokines [17]. Conversely, cPLA2 deficiency in $A D$ mouse models ameliorates the memory impairment and hyperactivated glial cells observed in $A D$ mouse models $[14,18]$. Knocking out cPLA2 in microglia decreases lipopolysaccharide (LPS) induced oxidative stress and inflammatory response [8].

Carrying the APOE4 allele is the strongest genetic risk factor for late-onset $A D$. The ApoE4 protein seems to have proinflammatory and/or reduced anti-inflammatory functions, which could exacerbate $A D$ pathology. This ApoE4 effect on inflammation was clearly demonstrated in the Framingham cohort, where participants with APOE4 and elevated plasma C-reactive protein (CRP) levels had a greater risk of developing late-onset of $A D$ than age and sex-matched $A P O E 2$ and $A P O E 3$ carriers [19]. In the brains of participants with $A D, A P O E 4$ is associated with greater levels of lipid peroxidation, eicosanoids, and oxidative stresses markers [20], but the mechanisms for these observations are not clear. Here, we hypothesized that ApoE4 activates CPLA2 to enhance AA release and eicosanoid levels, leading to an enhanced inflammatory and oxidative stress response. Accordingly, we examined cPLA2 expression and activation in mouse primary astrocytes, and in mouse and human brain samples that differed by $A P O E$ genotype and determined the cellular effects of cPLA2 inhibition on measurements of neuroinflammation and oxidative stress.

\section{Results}

\section{1. cPLA2 and phosphorylated cPLA2 are increased in ApoE4 mouse primary astrocytes}

We previously found that DHA/AA ratio in cerebrospinal fluid (CSF) is lower in APOE4/E4 carriers compared to $A P O E 3 / E 3$ carriers [21, 22]. Since astrocytic CPLA2 and iPLA2 enzymes are important determinants of brain AA and DHA metabolism $[2,23]$, these enzymes' expression and activity were first examined in primary astrocytes from ApoE-TR mice. ApoE4 astrocytes had greater mRNA and protein levels of cPLA2 and phosphorylated cPLA2 compared with ApoE3 astrocytes (Fig. 1A, B). In contrast, iPLA2 mRNA and protein levels did not differ between ApoE4 and ApoE3 primary astrocytes (Fig.1C, D). These measures were also significantly greater in ApoE4 immortalized astrocytes compared to ApoE3 (Fig. S1A and S1B). No differences were found in phosphorylated and total cPLA2 level between ApoE3 and ApoE4 primary microglial cells from ApoER-TR mice (Fig. S1C). To identify cellular cPLA2 localization, cytosolic and membrane fractions were obtained from primary ApoE astrocytes. As 
expected, the majority of cPLA2 was present in the cytosol. Both cytosolic and membrane-bound cPLA2 levels were greater in ApoE4 compared to ApoE3 (Fig. S2). To further explore the activities of cPLA2 and iPLA2, the efflux of ${ }^{3} \mathrm{H}-\mathrm{AA}$ or ${ }^{14} \mathrm{C}$-DHA from ApoE3 and ApoE4 primary astrocyte cells to media with or without ATP stimulation for 15 min was examined. ${ }^{3} \mathrm{H}$-AA efflux was significantly greater in stimulated ApoE4 compared to ApoE3 primary astrocytes (Fig. 1E), whereas ${ }^{14} \mathrm{C}$-DHA efflux showed no difference between ApoE4 and ApoE3 (Fig. 1F). To confirm the ApoE protein's effect, cultured primary astrocytes from C57BL/ 6 mice were labeled with ${ }^{3} \mathrm{H}-\mathrm{AA}$ or ${ }^{14} \mathrm{C}-\mathrm{DHA}$ and then treated with $0.2 \mu \mathrm{M}$ rApoE3 or rApoE4

proteins for $24 \mathrm{~h}$ under similar conditions to primary astrocytes cultured from ApoE-TR mice. ${ }^{3} \mathrm{H}$-AA efflux was greater after rApoE4 than rApoE3 treatment (Fig. 1G), whereas DHA efflux did not differ between rApoE4 and rApoE3 treatments (Fig. 1H). Taken together, these results confirmed that CPLA2 expression and activity were greater in ApoE4 compared to ApoE3 astrocytes.

\section{Phosphorylated CPLA2 and cPLA2 activity are increased in APOE4 mouse brains}

To investigate the effect of the ApoE isoforms on CPLA2 in vivo, MRNA, total protein, and phosphorylated protein levels of cPLA2 were measured in the cerebral cortex from 8-month-old ApoE3-TR and ApoE4-TR mice. There was no difference in cortical cPLA2 mRNA levels between ApoE3-TR and ApoE4-TR mice (Fig. 2A). Since phosphorylated cPLA2 levels were too low to detect in total brain homogenates, CPLA2 was enriched by immunoprecipitation with a cPLA2 antibody using $500 \mu \mathrm{g}$ of cortical homogenate, and total and phosphorylated cPLA2 levels were measured by Western blot. Total cPLA2 levels did not differ between ApoE3-TR and ApoE4-TR mouse cortex (Fig. 2B, C). However, phosphorylated cPLA2 was significantly increased in the ApoE4-TR mouse cortex compared to the ApoE3-TR mouse cortex (Fig. 2B, C). Consistent with these observations, cortical CPLA2 activity (based on the hydrolysis of the arachidonoyl thioester bond to release a detectable free thiol by endogenous brain PLA2) and leukotriene B4 (LTB4) levels (downstream product of AA release after CPLA2 activation) were higher in ApoE4-TR than ApoE3-TR mice (Fig. 2D, E).

\section{3. p38 MAPK but not ERK1/2 is increased in ApoE4 mouse primary astrocytes}

Phosphorylation of CPLA2 is regulated by MAPK pathways, including p38 MAPK and ERK1/2 MAPK [10, $24,25]$. We tested the phosphorylation of $p 38$ and ERK $1 / 2$ in primary astrocytes and mouse cortex from ApoE3 or ApoE4-TR mice by immunoblot using antibodies against total and phosphorylated proteins. Total p38 and ERK1/2 proteins did not differ between ApoE3 and ApoE4 primary astrocytes (Fig. 3A). Interestingly, only phosphorylated p38, but not phosphorylated ERK1/2, was significantly greater in ApoE4 primary astrocytes than ApoE3 primary astrocytes (Fig. 3A). In agreement, greater p38 phosphorylation but not ERK1/2 was evident in the cerebral cortex of 8-months old ApoE4-TR mice compared to ApoE3-TR mice (Fig. 3B). To test whether cPLA2 activation is dependent on p38 MAPK signaling, we treated ApoE4 
primary astrocytes with two different p38 MAPK pathway inhibitors (SB202190 and SB203580) prior to the induction of CPLA2 activation with TNFa and IFNy. The results showed that SB202190 significantly reduced phosphorylated (activated) cPLA2 levels (Fig. 3C). Interestingly, SB203580 had no inhibitory effects on cPLA2 activation (Fig. 3C), as SB203580 inhibited MAPKAPK-2 activity but not phosphorylation of p38 MAPK itself [26]. cPLA2 was found to be complexed with p38 as indicated by p38 co-immunoprecipitating with cPLA2 by anti-cPLA2 antibodies in immortalized ApoE4 astrocytes (Fig. 3D). These observations confirmed that 338 MAPK but not the ERK1/2 MAPK pathway can directly regulate CPLA2 phosphorylation.

\section{Phosphorylated cPLA2 is increased in APOE4 human brains}

Table 1 Characteristics of clinical samples

\begin{tabular}{|lllll|}
\hline Regions sampled and source & \multicolumn{4}{l}{ Inferior frontal lobe (ROSMAP, RUSH ADRC) } \\
\hline Clinical diagnosis & $\mathrm{AD}$ & $\mathrm{AD}$ & $\mathrm{NCl}$ & $\mathrm{NCl}$ \\
\hline Genotype & E3/E3 & E3/E4 & E3/E3 & E3/E4 \\
\hline Sample size, $\mathrm{n}$ & 12 & 10 & 12 & 10 \\
\hline Age (years \pm SD) * & $92 \pm 6$ & $95 \pm 5$ & $83 \pm 5$ & $85 \pm 4$ \\
\hline Sex (n, female/male) * & $5 / 7$ & $6 / 4$ & $6 / 6$ & $5 / 5$ \\
\hline Braak stage & IV & $\mathrm{V}$ & III & III \\
\hline
\end{tabular}

*Age and gender did not differ between groups compared using ANOVA. $\mathrm{NCl}=$ no cognitive impairment. $A D=$ Alzheimer's disease.

To determine whether these findings can be demonstrated in human brains, we compared phosphorylated and total CPLA2 in the inferior frontal cortex of persons with a similar clinical diagnosis but with different $A P O E$ genotypes. Characteristics of brain samples tested are summarized in Table 1. After enrichment of CPLA2 from the cortex, phosphorylated and total CPLA2 levels were measured by western blot. In the $\mathrm{NCl}$ group, total CPLA2 did not significantly differ between the APOE3/E3 and $A P O E 3 / E 4$ carriers, while the phosphorylated CPLA2 level showed a trend increase in APOE3/E4 carriers compared to $A P O E 3 / E 3$ carriers (Fig. 4A). In patients with AD, phosphorylated cPLA2 levels were significantly greater in APOE3/E4 carriers compared with APOE3/E3 carriers ( $\mathrm{p}=0.039)$, while the total cPLA2 levels did not differ between the two groups (Fig. 4B). Greater CPLA2 phosphorylation in the $A P O E 3 / 4$ group was not affected by sex, age, or Braak stage. A nonsignificant difference in soluble Ab42 monomers $(\mathrm{p}=0.12$ ) was observed in the brains of $A P O E 3 / E 4$ carriers compared with $A P O E 3 / E 3$ carriers with AD (Fig. S3). 


\section{5. p38 MAPK is increased in APOE4 human brain samples}

Previous results from mouse astrocyte and cortex showed increased p38 activation in ApoE4-TR compared to ApoE3-TR mice. Phosphorylated and total p38 levels did not differ between NCI APOE3/E3 and $\mathrm{NCl} A P O E 3 / E 4$ groups (Fig. $5 \mathrm{~A}$ ), while total p38 level was significantly greater in the AD APOE3/E4 group compared with the AD APOE3/E3 group (Fig. 5B). In a second brain cohort from the USC ADRC neuropathology core (Supplementary table 1), nonsignificant differences were observed in phosphorylated cPLA2/total CPLA2 in the hippocampus of the APOE4/E4 AD group compared to the $A P O E 3 / E 3 \mathrm{NCl}$ group (Fig. S4A), despite a significantly greater ratio of phosphorylated p38/ total p38 in the APOE4/E4 AD group (Fig. S4B). These results supported the greater activation of p38 MAPK pathway with ApoE4 that was most prominent in persons with $A D$.

\section{LTB4 levels are increased in APOE4 human brain samples}

AA is released by CPLA2 hydrolysis of membrane phospholipids, and then can be rapidly oxidized by COX or LOX enzymes to prostaglandins or leukotrienes (LTB4 and PGE2), potent mediators of inflammation and signal transduction [2]. To test the effect of the greater CPLA2 phosphorylation in APOE4 AD brains, PGE2 and LTB4 levels were assayed in brain homogenates from the inferior frontal cortex. LTB4 levels were significantly greater in the AD APOE3/4 group compared with the $A D A P O E 3 / 3$ group $(p=0.01)$ (Fig. $6 \mathrm{~A}$ ), while PGE2 levels did not differ between the two groups (Fig. 6B). The greater LTB4 levels in APOE3/E4 group were also not affected by sex, age, or Braak stage. No significant differences were found in either LTB4 or PGE2 levels between the $\mathrm{NCl} A P O E 3 / 3$ and $\mathrm{NCl} A P O E 3 / 4$ groups (Fig. $6 \mathrm{C}$ and D). The expression of 5-LOX and COX-2 did not differ between the AD APOE3/3 and AD APOE3/4 groups (Fig. $6 E)$. These results indicated that ApoE4's activation of CPLA2 in AD selectively increased LTB4 levels in the AD brain.

\section{The NF-kB inflammasome is not induced in the APOE4 brain}

It is not clear whether APOE4 can induce neuroinflammation via activation of the NF-kB inflammasome in vivo, and whether CPLA2 is involved in this pathway. Although we found greater TNFa mRNA levels in ApoE4 than in ApoE3 astrocytes, IL 1b, IL6 and Ccl2 did not differ between ApoE3 and ApoE4 astrocytes (Fig. 7A). In addition, the protein levels of these cytokines and chemokines were comparable in different ApoE genotypes in the mouse brains (Fig. 7B) or the human brain samples (Fig. 7D). Similarly, the abundance of glial fibrillary acid protein (GFAP) in astrocytes and ionized calcium binding adaptor molecule 1 (Iba1) in microglia also did not differ by genotype (Fig. 7D-E). No associations were found between the p-cPLA2/cPLA2 ratio and the GFAP or Iba1 levels in human cortex samples (Fig. S5). The 
greater LTB4 levels in APOE3/E4 group were also not affected by sex, age, or Braak stage. These results indicated that neuroinflammation with APOE4 does not favor the NF-kB inflammatory response pathway.

\section{8. cPLA2 is involved in the ApoE4 mediated up-regulation of LTB4 and ROS}

To explore whether CPLA2 inhibition mitigates the downstream effects of LTB4 production on ROS and iNOS, ApoE3 and ApoE4 primary astrocytes were treated with the CPLA2 inhibitor pyrrophenone (Fig 8A). Treatment with pyrrophenone reduced LTB4 levels in ApoE3 and ApoE4 astrocytes, but to a greater extent in ApoE4 astrocytes (Fig. 8B). Furthermore, CPLA2 inhibition significantly decreased iNOS and ROS levels in ApoE3 and ApoE4 primary astrocytes (Fig. 8C, D). These results indicated that greater CPLA2 activity promoted greater levels of iNOS and ROS in the ApoE4 group and can be reduced with CPLA2 inhibition. To confirm the specific effect of CPLA2 in LTB4 production, we knocked down CPLA2 by small interfering RNA (siRNA) in ApoE4 primary astrocytes (Fig. 8E). In agreement, LTB4 levels were significantly decreased in the CPLA2 siRNA treatment group compared to the non-target siRNA treatment group (Fig. $8 \mathrm{~F})$.

\section{ApoE4 and Ab induce cPLA2 activation in human postmortem frontal cortical synaptosomes}

Since CPLA2 was shown to be expressed in neurons and activated by Ab monomers[27], we examined the effect of exogenous $A b_{42}$ and $A p o E$ on its activation in synaptosomes from human postmortem frontal cortices obtained from control participants without $A D$ pathology. The results showed that treatment with $\mathrm{Ab}_{42}, \mathrm{ApoE} 4, \mathrm{ApoE} 4 / \mathrm{Ab}_{42}$ or ApoE3 individually had no effect on cPLA2 activation and distribution in cytosol and membrane of the synaptosomes (Fig. 9A, B). However, pretreatment with Ab ${ }_{42}, A p o E 4$ and $\mathrm{Ab}_{42}$ plus ApoE4 significantly prevented TNFa+IFNy-evoked cPLA2 cytosol to membrane translocation leading to an increase in phosphorated CPLA2/CPLA2 ratio in the membranous fraction of synaptosome but a decrease in the cytosolic phosphorylated cPLA2/cPLA2 ratio. ApoE3 had no effect on cPLA2 activation (Fig. 9A, C). In contrast to TNFa+IFNy, ceramide-1-phosphate did not alter cPLA2 cellular distribution. $A b_{42}, A p o E 4$ and $A b_{42}$ plus ApoE4 significantly enhanced phosphorylated cPLA2 levels in the cytosolic but had no effect on the membranous cPLA2 (Fig. 9A, D). Taken together, these results indicated that ApoE4 and $\mathrm{Ab}_{42}$ could induce $\mathrm{CPLA} 2$ activation in neurons and astrocytes, suggesting that greater CPLA2 activitation in the human cortex of AD E3/E4 compared to AD E3/E3 might arise from the combined effects of ApoE4 and greater $\mathrm{Ab}_{42}$ accumulation.

\section{Discussion}

Despite multiple past observations associating $A P O E 4$ with greater neuroinflammatory and oxidative stress response than $A P O E 2$ or $A P O E 3$ (Table 2), the underlying mechanisms are not clearly understood. Here, we identify a plausible mechanism where APOE4 induces greater activation of the CPLA2 system in 
both astrocytes and synaptosomes, with greater release of AA, LTB4, iNOS, and generation of ROS in astrocytes. The increase in LTB4 in APOE4 was corroborated in human brain samples matched by disease state. Inhibition of CPLA2 activity lowered the greater neuroinflammation associated with APOE4, reinforcing the candidacy of CPLA2 as a therapeutic target for mitigating the increase in AD risk conferred by carrying $A P O E 4$.

Table 2. Summary of the association of $A P O E 4$ with greater neuroinflammation. 


\section{Author Key findings}

\section{Cultures (microglia, astrocytes, or mixed cultures) and inflammatory response by genotype}

Vitek et al. Microglia derived from ApoE4-TR mice demonstrate increased NO production, [28] increased NOS2 mRNA levels, and greater TNFa, IL-6, IL12 levels compared to microglia from ApoE3-TR mice.

Colton et al. Significantly more NO was produced in primary microglia and macrophages from [29] ApoE4-TR mice compared to ApoE3-TR mice.

Guo et al.

[30]

The addition of exogenous ApoE4 induced greater IL1 $\beta$ than apoE3 in rat mixed glial cells.

Chen et al.

[31]

ApoE4, but not ApoE3, stimulated secretion of PGE2 and IL-1 $\beta$ in rat primary microglia.

Shi et al.

[32]

Higher TNFa, IL1 $\beta$, and IL1a levels were observed in primary microglia from ApoE4-TR mice stimulated with LPS than ApoE2 and ApoE3.

Tai et al. Greater astrogliosis and microgliosis, higher levels of IL1 $\beta$ in E4FAD mice compared [33] with E3FAD and E2FAD mice.

Zhu et al. Higher levels of microglia/macrophage, astrocytes, and invading T-cells after LPS [34] injection in ApoE4-TR mice than ApoE3-TR mice. ApoE4-TR mice also displayed greater and more prolonged increases of cytokines (IL1 $\beta$, IL6, TNFa) than ApoE2 and ApoE3-TR mice.

Ophir et al.

[35]

The expression of inflammation-related genes (NF-KB response elements) following intracerebroventricular injection of LPS was significantly higher and more prolonged in ApoE4 than in ApoE3-TR mice.

\section{Both human and mouse models}

Gale et al. ApoE4-TR mice displayed enhanced plasma cytokines after systemic LPS compared [36] with ApoE3 counterparts. After intravenous LPS, APOE3/4 patients had higher plasma TNF-a levels than APOE3/3 patients.

\section{Human brain studies of inflammation and oxidative stress studies by APOE genotype}

Montine at Pyramidal neuron cytoplasm was immunoreactive for 4-hydroxy-2-nonenal (HNE) in al [37] 4 of 4 APOE4 homozygotes, 2 of 3 APOE3/4 heterozygotes, and none of 3 APOE3 homozygotes

Ramassamy In hippocampal homogenates from AD brains, APOE4 carriers had greater levels of et al. [20] thiobarbituric acid-reactive substances (TBARS), lower catalase activities, and glutathione peroxidase and glutathione than tissues from patients homozygous for the $A P O E 3$ allele ( $n=10$ per group).

Egensperger et al. [38]

The number of activated microglia and the tissue area occupied by these cells increased significantly with the APOE4 gene dose $(\mathrm{n}=20)$.

Minett et al. [39]

Friedberg et al. [40]
APOE4 allele was significantly related to greater expression of CD68, HLA-DR, and CD64 in microglia $(n=299)$.

Cellular density of microglial marker-lba1 was positively associated with tau pathology in APOE4 carrier participants only $(n=154)$. 


\section{Systemic inflammation and dementia risk by genotype}

Tao et al. Participants with APOE4 and elevated plasma $\mathrm{C}$ reactive protein (CRP) levels had a [19] shortened latency for the onset of $A D(n=2562)$.

There is evidence from clinical studies implicating greater CPLA2 activation around AD brain plaques [12]. cPLA2 activity is also increased in the CSF of patients with AD [41]. CPLA2 activation can be indirectly assessed by the release of AA from membrane phospholipids [2]. ${ }^{11} \mathrm{C} A A$ brain uptake by PET and unesterified AA/DHA measurement in CSF are surrogate brain CPLA2 activity markers. Indeed, greater incorporation coefficients of ${ }^{11} \mathrm{C}$ AA by PET scans were observed in the grey-matter regions of the brain of $A D$ patients compared to control subjects [42]. Moreover, a greater AA/DHA ratio in both CSF and plasma was present in $A P O E 4$ carriers with mild AD compared to $A P O E 3$ carriers after DHA supplementation [21]. A greater AA/DHA ratio in plasma phospholipids in cognitively healthy APOE4 carriers was associated with greater conversion to MCI/AD [43]. The greater plasma AA/DHA in APOE4 suggests a systemic (for example, in the liver) activation of CPLA2 that is not just confined to the brain.

Our studies in human brains revealed that carrying an APOE4 allele is not sufficient to activate CPLA2. This is not surprising as not all APOE4 carriers develop AD pathology. CPLA2 activation was significantly greater in $A P O E 4$ carriers compared to $A P O E 3$ carriers with $\mathrm{AD}$, but not in those with $\mathrm{NCl}$. We also found recombinant ApoE4 and Ab42 induced greater activation of cPLA2 in post mortem frontal lobe synaptosomes (Fig. 9). One biological explanation is that the effects of soluble Ab oligomers in AD is additively intensified by ApoE4 to promote a neuroinflammatory phenotype. We speculate that treatments which reduce activation of CPLA2 especially in APOE4 carriers can protect these subjects from neuroinflammation and neurodegeneration, but this hypothesis is yet to be proven. In contrast to observations made in human brains, the activation of CPLA2 in APOE4 KI mouse models in both primary astrocytes and animal brains was measured independent of Ab. The APOE4 KI mouse models used here are $A P O E 4$ homozygous and are maintained under a controlled environment that can allow for observing a greater APOE4 effect than observed with human studies.

Greater CPLA2 activation is mechanistically involved in AD pathology and may represent one pathophysiological link between $A \beta$ oligomers and neuroinflammatory responses [44]. An increase of phosphorylated cPLA2 but not of total CPLA2 was observed in the brains of AD mouse models compared with WT mice [14]. In vitro studies suggested that Ab oligomers can trigger CPLA2 activation and PGE2 production in neurons, eventually leading to neurodegeneration [27, 45]. Inhibition of cPLA2 prevented synaptic loss and memory deficits induced by Ab oligomers in mice [46]. Similar to Ab, there is evidence that human prion peptide can also induce neurotoxicity by activating CPLA2, which can be prevented by cPLA2 inhibition [47]. In support of greater CPLA2 activity, hippocampal levels of AA and AA-derived metabolites were much greater in hAPP mice than in non-transgenic control mice [48]. 
The pattern of enhanced neuroinflammation of the APOE4 AD brains observed in this study does not support the induction of the NF-KB inflammasome by cytokines or chemokines such as TNFa, IL1b, IL6, and $\mathrm{Cc} 2$, as past findings supporting these activation patterns were mostly a result of high doses LPS injections in cell culture and in vivo animal models (summarized in Table 2). Instead, we found a greater level of LTB4 in the cerebral cortex of AD with E3/E4 carriers compared to E3/E3 carriers and ApoE4 astrocytes, which was associated with the greater phosphorylation of CPLA2. These observations provide a mechanism for the greater levels of oxidative stress in the APOE4 brain [20,37]. It is plausible that astrocytes contribute to the greater LTB4, ROS, and iNOS production with APOE4. An extensive recent proteomic and lipidomic investigation in animal brains of ApoE-TR mice corroborates the enhanced eicosanoid signaling with APOE4 [49]. LTB4 signaling may have a prominent role in inducing oxidative stress. Chuang et al. reported that ROS and NO production during microglia activation is reduced by inhibition of lipoxygenase but not cyclooxygenase [8], suggesting induced LOX signaling as the primary driver of oxidative stress.

Activation of cPLA2 may differ by cell type and within cellular compartments. Recently, astrocytic activation of CPLA2 bound directly with MAVS enhanced NF-KB pathways to produce proinflammatory factors such as $\mathrm{Ccl} 2$ and Nos2 in an animal model of multiple sclerosis (MS) [7]. The fact that we did not observe greater CcL2 or Nos2 expression in APOE4 astrocytes, mouse, or human brains in our current study suggests the selective activation CPLA2 by location within the astrocyte leading to a distinct neuroinflammatory phenotype. In addition to MS, the increase in AA release and its metabolism to prostaglandins and leukotrienes have been observed in cancers and other neurodegeneration diseases [50-52]. For example, PIK3CA mutant breast cancer tumor cells displayed dramatically elevated AA and eicosanoid levels, promoting tumor cell proliferation [51].

The activation of MAPK system by ApoE4 likely involves complex set of ApoE receptors or signaling pathways. In neurons, ApoE4 was shown to produce greater activating of the MAPK/ERK system (isoform dependent manner) to induce greater production of APP[53], however, it was not clear if this activation involved ApoE signaling receptors (e.g., ApoER2 and VLDLR) or metabolic receptors (e.g., LRP1 and LDLR). Further studies are needed to sort out the receptor(s) involved in different cell types. That could help elucidate the physiological and pathological pathways relevant to ApoE and/or the receptors and their effect of P38-cPLA2 signaling.

Activation of CPLA2 activity is associated with its phosphorylation [10]. CPLA2 phosphorylation is regulated by ERKs and p38 MAPK pathways, which phosphorylates CPLA2 at Ser-505 and increases its 
enzymatic activity [9]. CPLA2 phosphorylation and AA release in response to PMA and ATP stimulation in mouse astrocytes are mediated by ERKs and p38 MAPK pathways [10]. In the platelets, cPLA2 phosphorylation was induced by p38 MAPK activation [24]. Here, we found that ApoE4 selectively activated p38 but not ERKs, and inhibition of p38 in ApoE4 astrocytes decreased cPLA2 activation. This activation of p38 is consistent with a previous report of greater p38 activation but not ERKs pathway in ApoE4-TR mice [54]. Interestingly, p38 inhibitors are in drug development pipelines for AD [55].

Our study has several strengths and some limitations. We confirmed our findings of greater cPLA2 activation in several independent models: primary cells, synaptosomes, in ApoE-TR animal models, and in human brains matched by disease stage and differing by genotype. We identified the signaling pathway involved in cPLA2 activation- (MAPK-p38) and validated this in both animal and human brains. Some of the limitations include not defining the cell-specific cPLA2 activation profile in vivo (whether derived from astrocytes, microglia, neurons and oligodendrocytes). In the clinical cohort, we did not study cPLA2 expression in $A P O E 4$ homozygote patients without cognitive impairment, as this condition is infrequent. We also acknowledge that the small sample sizes the human brain cohort that can preclude the full examination of the effect of sex and other AD risk factors on the association between APOE 4 and neuroinflammation. Future studies will include larger sample sizes and more specific approaches (such as single-cell sequencing) to capture CPLA2's activation fingerprint on different brain cell types.

\section{Conclusions}

Overall, using multiple approaches, our study has identified that the activation of cPLA2 is implicated in neuroinflammation and oxidative stress associated with APOE4 (Fig 10). Our findings support the induction of the MAPK-p38 pathway as the driving factor for the activation of the CPLA2-LTB4 signaling cascade, and our cellular studies prioritize astrocytes as the target cell type. Inhibition of brain CPLA2 signaling may provide an attractive strategy to reduce the risk of $A D$ dementia associated with carrying the APOE4 allele.

\section{Materials And Methods}

\section{Clinical Samples}

The frozen hippocampi of $A D$ patients with APOE4/E4 carriers $(\mathrm{N}=9)$ and no-cognitive impairment (NCl) with $A P O E 3 / E 3$ carriers $(\mathrm{N}=7)$ were collected from the University of Southern California (USC) Alzheimer Disease Research Center (ADRC) Neuropathology core, which was approved by USC's Institutional Review Board (IRB) protocol (HS-16-00888). The frozen inferior frontal lobe (Brodmann area 10) of the individuals with $\mathrm{NCl}$ and the $A P O E 3 / E 3$ carriers $(\mathrm{N}=12)$ and $A P O E 3 / E 4$ carriers $(\mathrm{N}=10)$ and persons with $A D$ patients and the APOE3/E3 $(\mathrm{N}=12)$ and $A P O E 3 / E 4$ genotypes $(\mathrm{N}=10)$ were obtained from the Rush 
Alzheimer's Disease Center (RADC) at the Rush University Medical Center. Rush Memory and Aging Project was approved by an Institutional Review Board (IRB) of Rush University Medical Center.

\section{Animals}

ApoE3-TR and ApoE4-TR mice were a generous gift from Dr. Patrick Sullivan. The endogenous mouse ApoE was replaced by either human APOE3 or APOE4, created by gene targeting, as described previously [56]. All experiments were performed on age-matched male animals (8 months of age) and were approved by the USC Animal Care Committee. Every effort was made to reduce animal stress and to minimize animal usage. The mice were anesthetized with isoflurane and perfused with PBS. The brains were split in half for further analysis.

\section{Cell cultures}

Primary astrocytes were obtained from C57JB6, ApoE3-TR, and ApoE4-TR mice pups and cultured, as described previously[57]. Briefly, cerebral cortices from each 1 to 3 day-old neonatal mouse were dissected in ice-cold Hanks' Balanced Salt Solution (HBSS) (Corning, 21-021-CV) and digested with 0.25\% trypsin for $20 \mathrm{~min}$ at $37^{\circ} \mathrm{C}$. Trypsinization was stopped by the addition of a 2 -fold volume of DMEM (Corning, 10-013) with $10 \%$ fetal bovine serum (FBS) (Omega Scientific, FB-12) and $1 \%$ antibioticantimycotic (Anti-anti) (Thermo Fisher, 15240062). The cells were dispersed into a single-cell level by repeated pipetting and filtered through $100 \mathrm{~mm}$ cell strainers (VWR, 10199-658). After filtering, cells were centrifuged for $5 \mathrm{~min}$ at $1000 \mathrm{rpm}$ and resuspended in a culture medium supplemented with $10 \%$ FBS and antibiotics. Then, cells were seeded in a $75 \mathrm{~cm}^{2}$ flask and cultured at $37^{\circ} \mathrm{C}$ in $5 \% \mathrm{CO}$. The medium was changed on the next day and then replaced every 3 days. These mixed glia cultures reached confluence after $7-10$ days. The cells were then shaken at $250 \mathrm{rpm}$ for $16 \mathrm{~h}$ at $37^{\circ} \mathrm{C}$ to remove microglia and oligodendrocyte progenitor cells. The remaining cells were harvested by digestion with trypsin. At this stage, the culture contained $95 \%$ astrocytes and was used for further experiments.

Immortalized mouse astrocytes derived from human ApoE3 and ApoE4 knock-in mice [58] were gifts from Dr. David Holtzman and grown in DMEM/F12 (Corning, MT10090CV) containing 10\% FBS, $1 \mathrm{mM}$ sodium pyruvate (Thermo Fisher, 11360070), $1 \mathrm{mM}$ geneticin (Thermo Fisher, 10131-035) and 1\% anti-anti.

\section{Cell lysate and brain homogenate preparation}

The immortalized or primary astrocytes were lysed with 1x RIPA buffer (Cell Signaling Technology, CST 9806) containing protease inhibitor cocktail (Sigma, P8340) and phosphatase inhibitor cocktail (Sigma, P0044), followed by centrifugation at 14,000 gs for $10 \mathrm{~min}$ at $4{ }^{\circ} \mathrm{C}$. The supernatant was collected for further analysis. 
The mouse cerebral cortex, human hippocampus, and inferior frontal cortex were weighed, then RIPA buffer containing protease inhibitor cocktail and phosphatase inhibitor cocktail was added as 1:30 (w/v). The tissue was then homogenized using a $2 \mathrm{~mL}$ glass Dounce tissue grinder, followed by centrifugation with 14,000 gs for $10 \mathrm{~min}$ at $4{ }^{\circ} \mathrm{C}$. The supernatant was collected, and the concentration was measured by BCA kit.

\section{cPLA2 protein enrichment}

To detect the phosphorylated cPLA2 in mouse cortex homogenates, CPLA2 protein was enriched by immunoprecipitation. For each mouse sample, $5 \mu \mathrm{g}$ of cPLA2 antibody (Santa Cruz Biotechnology, sc376618) was conjugated to $50 \mu \mathrm{L}$ Dynabeads Protein G (Thermo Scientific, 10003D) for $1 \mathrm{hr}$ at room temperature, then $500 \mu \mathrm{g}$ total protein in 500 $\mu \mathrm{L}$ RIPA was added to the cPLA2-beads complex and incubated with rotation overnight at $4{ }^{\circ} \mathrm{C}$. The beads were washed with $0.1 \%$ PBST 3 times by rotation for $5 \mathrm{~min}$. After washing, $30 \mu \mathrm{L}$ of $1 \mathrm{x}$ sample buffer (Bio-Rad, 1610747) was added to the beads and heated for 10 minutes at $100^{\circ} \mathrm{C}$. The supernatant was collected by magnetic force and used for the further Western-blot assay.

\section{Western blot}

The cell lysates, cortex homogenate, and enriched cPLA2 proteins were separated by $4-15 \%$ mini-precast protein gels (Bio-Rad, 4561086) under reducing conditions and then transferred onto nitrocellulose membranes (Bio-Rad, 1704270). After transfer, membranes were blocked with $5 \%$ fat-free milk (Bio-Rad, 1706404) in TBST for $1 \mathrm{~h}$ at room temperature, followed by overnight incubation with the primary antibody in $5 \% \mathrm{BSA}$ at $4^{\circ} \mathrm{C}$. Then, the membranes were incubated with HRP conjugated secondary antibody for $1 \mathrm{~h}$ at room temperature. Chemiluminescent HRP substrate (Millipore, WBKLS0500) was used for detection. Fujifilm LAS-4000 imager system was used to capture images, and the densitometric quantification was done by Gel Quant NET software.

The following antibodies and dilution factors were used: CPLA2 antibody (Santa Cruz Biotechnology, sc376618) (1:200), phospho-cPLA2 (Ser505) antibody (CST, 53044) (1:1000), phospho-ERK1/2 antibody (CST, 4370) (1:1000), ERK1/2 antibody (CST, 4595) (1:1000), p38 antibody (CST, 9212) (1:1000), phospho-p38 antibody (CST, 4511) (1:1000), GFAP antibody (CST, 12389) (1:1000), Iba-1 antibody (GeneTex, GTX100042) (1:1000), iNOS antibody (CST, 13120) (1:1000), $\beta$-actin antibody (CST, 3700) (1:1000), $\beta$-tubulin antibody (CST, 2146) (1:1000), HRP-linked anti-mouse IgG (CST, 7076) (1:2000), HRPlinked anti-rabbit IgG (CST, 7074) (1:2000).

$q P C R$ 
The cells and brain specimens were harvested, and RNA was extracted using an RNA extraction kit (Thermo Fisher, K0731). Synthesis of cDNA was done using High-Capacity cDNA Reverse Transcription Kit (Thermo Fisher, 4368814). qPCR was performed using the PowerUp SYBR Green Master Mix (Thermo Fisher, A25742). The following primers were synthesized by Integrated DNA Technologies. The cPLA2 sense (5'-CTGCAAGGCCGAGTGACA-3') and antisense (5'-TTCGCCCACTTCTCTGCAA-3'); mouse Tnfa sense (5'-GCCTCTTCTCATTCCTGCTTG-3') and antisense (5'-CTGATGAGAGGGAGGCCATT-3'); mouse Il1 b sense (5'-GCAACTGTTCCTGAACTCAACT-3') and antisense (5'-ATCTTTTGGGGTCCGTCAACT-3'); mouse $\| 6$ sense (5'-TAGTCCTTCCTACCCCAATTTCC-3') and antisense (5'-TTGGTCCTTAGCCACTCCTTC-3'); mouse Ccl2 sense (5'-GTCCCTGTCATGCTTCTGG-3') and antisense (5'-GCTCTCCAGCCTACTCATTG-3'); mouse Mip1a sense (5'- TGAAACCAGCAGCCTTTGCTC-3') and antisense (5'AGGCATTCAGTTCCAGGTCAGTG-3'); mouse Mip2 sense (5'-ATCCAGAGCTTGAGTGTGACGC-3') and antisense (5'- AAGGCAAACTTTTTGACCGCC-3'); mouse b-actin sense (5'-ACCTTCTACAATGAGCTGCG-3') and antisense (5'-CTGGATGGCTACGTACATGG-3'); human TNFa sense (5'-ACTTTGGAGTGATCGGCC-3') and antisense (5'-GCTTGAGGGTTTGCTACAAC-3'); human IL1b sense (5'-ATGCACCTGTACGATCACTG-3') and antisense (5'-ACAAAGGACATGGAGAACACC-3');

human IL6 sense (5'-CCACTCACCTCTTCAGAACG-3') and antisense (5'-CATCTTTGGAAGGTTCAGGTTG3'); human CCL2 sense (5'- TGTCCCAAAGAAGCTGTGATC-3') and antisense (5'-

ATTCTTGGGTTGTGGAGTGAG-3'); human GAPDH sense (5'-ACATCGCTCAGACACCATG-3') and antisense (5'-TGTAGTTGAGGTCAATGAAGGG-3')

\section{$A A$ and DHA efflux assays}

To investigate arachidonic acid (AA) and docosahexaenoic acid (DHA) release by cPLA2 and iPLA2 activation, respectively, we performed an AA and DHA efflux assay as described previously [2]. ApoE3 and ApoE4 primary astrocytes were seeded at 5000 cells/well in 96-well plates. After $24 \mathrm{~h}$, the culture medium was changed with serum-free DMEM containing fatty acid-free BSA $(5 \mathrm{mg} / \mathrm{mL})$ (Sigma, A9647) and ${ }^{3} \mathrm{H}-\mathrm{AA}$ $(1 \mu \mathrm{Ci} / \mathrm{mL})$ or ${ }^{14} \mathrm{C}-\mathrm{DHA}(1 \mu \mathrm{Ci} / \mathrm{mL})$ (Moravek) for $24 \mathrm{~h}$. The cells were then washed twice with $100 \mu \mathrm{L}$ of DMEM, and $100 \mu \mathrm{L}$ of DMEM containing BSA $(5 \mathrm{mg} / \mathrm{mL})$ was added. After 30 minutes, the medium was removed, and $100 \mu \mathrm{L}$ of ATP $(100 \mu \mathrm{M})$ in DMEM without BSA was added. After 15 minutes, the cell culture medium was collected and transferred to scintillation vials filled with $3 \mathrm{~mL}$ of scintillation cocktail. The cells were solubilized in $90 \mu \mathrm{L}$ of $\mathrm{NaOH}(0.5 \mathrm{~N})$ for 5 minutes, neutralized with $60 \mu \mathrm{L}$ PBS, and then transferred to scintillation vials filled with $3 \mathrm{~mL}$ scintillation cocktail. After rigorous mixing, the vials were counted in a Beckman LS6500 liquid scintillation counter (Beckman Coulter). The efflux of AA and DHA were assessed by the ratio of the corresponding fatty acid in the medium to total (medium and cell lysate). The change of AA and DHA efflux was calculated by subtracting the levels of AA and DHA in the ATP treated group to ATP non-treated group for each genotype. WT primary astrocytes were plated and labeled with ${ }^{3} \mathrm{H}-\mathrm{AA}(1 \mu \mathrm{Ci} / \mathrm{mL})$ or ${ }^{14} \mathrm{C}-\mathrm{DHA}(1 \mu \mathrm{Ci} / \mathrm{mL})$ as described above. Then, the cells were washed twice with $100 \mu \mathrm{L}$ of DMEM. After wash, $10 \mu \mathrm{L}$ of DMEM containing BSA and $0.2 \mu \mathrm{M}$ recombinant ApoE3 
or ApoE4 protein were added. After $24 \mathrm{~h}$, the medium was removed, and $100 \mu \mathrm{L}$ of ATP $(100 \mu \mathrm{M})$ in DMEM without BSA was added. The AA and DHA efflux were measured as described above after 15 minutes.

cPLA2 activity assay

cPLA2 activity was detected by the cPLA2 activity assay kit (Cayman Chemical, 765021). The mouse cortex was homogenized into HEPES buffer ( $50 \mathrm{mM}, \mathrm{pH} 7.4$, containing $1 \mathrm{mM}$ EDTA) as 1:10 (w/v), and the supernatant was collected after centrifuged and used for CPLA2 activity detection.

\section{Immunoprecipitation}

Immortalized ApoE4 astrocytes were cultured in a 100-mm dish for 18 hours and then were lysed with RIPA containing protease and phosphatase inhibitors. The lysates were used for immunoprecipitation with an anti-cPLA2 antibody or species-matched IgG. After elution, CPAL2 and p38 were detected by Western-blot.

\section{p38 MAPK inhibiton experiment}

ApoE4 primary astrocytes were seeded in a 24-wells plate with the intensity of 100,000 cells per well. Forty-eight hours later, cells were pre-treated with p38 MAPK inhibitors - SB202190 (10 MM, Sigma, S7076) or SB203580 $(10 \mu \mathrm{M}$, Sigma, S8307) in the DMEM culture medium without FBS for 20 minutes, followed by the treatment with vehicle or TNFa (10ng/mL) (R\&D Systems, 210-TA-005) plus IFNg $(100 \mathrm{ng} / \mathrm{mL})$ (Sigma, SRP3058) together for 30 minutes. Then, the cells were lysed with RIPA. Total and phosphorylated cPLA2 and p38 were detected by Western-blot.

\section{LTB4 and PGE2 measurement}

For the LTB4 and PGE2 measurements in the human brain samples, brain tissue was weighed, then PBS containing $1 \mathrm{mM}$ EDTA, $10 \mu \mathrm{M}$ indomethacin (Cox inhibitor, Sigma 18280), and $10 \mu \mathrm{M}$ NDGA (Lox inhibitor, Sigma 479975) as 1:10 (w/v) were added. The tissue was then homogenized using a $2 \mathrm{~mL}$ glass Dounce tissue grinder, followed by centrifugation with $8,000 \times \mathrm{g}$ for 10 minutes at $4{ }^{\circ} \mathrm{C}$. The supernatant was collected, and the protein concentration was measured using a BCA kit. LTB4 and PGE2 levels were detected by the assay kit (LTB4 ELISA Kit, Cayman Chemical, 10009292; PGE2 ELISA Kit, Cayman Chemical, 500141). 
For the LTB4 measurement in the cells, ApoE3 and ApoE4 primary astrocytes were seeded in a 24-wells plate with the intensity of 100,000 cells per well. Forty-eight hours later, cells were pre-treated with cPLA2 inhibitor-Pyrrophenone (500nM, Sigma, 5305380001) in the DMEM culture medium without FBS but containing N2 supplement for 30 minutes, followed by the treatment with vehicle or TNFa $(10 \mathrm{ng} / \mathrm{mL})$ (R\&D Systems, 210-TA-005) plus IFNg (100ng/mL) (Sigma, SRP3058) together for 18 hours. Then, the culture media and cell lysate were collected. LTB4 levels were measured in a 4 -fold concentrated medium using the assay kit.

ApoE4 primary astrocytes were seeded in a 24-wells plate with the intensity of 100,000 cells per well. Forty-eight hours later, cells were transfected with cPLA2 or non-target (NT) siRNA (10nM) for 48 hours, followed by the treatment with vehicle or TNFa $(10 \mathrm{ng} / \mathrm{mL})$ plus IFNg $(100 \mathrm{ng} / \mathrm{mL})$ together for 24 hours. Then, the culture media and cell lysate were collected. LTB4 levels were measured in a 4-fold concentrated medium by the assay kit.

\section{ROS measurement}

ROS were detected by the DCFDA cellular ROS detection assay kit (Abcam, ab113851). ApoE3 and ApoE4 primary astrocytes were seeded in dark, clear bottom 96-wells plate with the intensity of 20,000 cells per well. Forty-eight hours later, cells were pre-treated with cPLA2 inhibitor $(1 \mu \mathrm{M})$ in the DMEM culture medium without FBS but containing N2 supplement for 30 minutes, followed by the treatment with vehicle or TNFa $(10 \mathrm{ng} / \mathrm{mL})$ plus IFNg $(100 \mathrm{ng} / \mathrm{mL})$ together for 24 hours. After removing the media and washing plate once with $1 \mathrm{x}$ assay buffer, the cells were stained with DCFDA solution (100 $\mu \mathrm{L} /$ well) for 45 minutes at $37^{\circ} \mathrm{C}$ in the dark. Then, the DCFDA solution was removed, and the $1 \mathrm{x}$ assay buffer $(100 \mu \mathrm{L} /$ well) was added to the plate. ROS levels were measured using a fluorescent plate reader at Excision/Emission=485/585nm.

\section{Assessment of activation and cellular distribution of CPLA2 in synaptosomes}

Synaptosomes prepared from postmortem human frontal cortices using an established method with minor modification[59]. Briefly, thawed postmortem human frontal cortical slices (about $20 \mathrm{mg}$ ) were homogenized in 10 volume of ice-cold homogenization buffer ( $10 \mathrm{mM} \mathrm{HEPES,} \mathrm{pH} \mathrm{7.4,} \mathrm{0.32} \mathrm{M} \mathrm{sucrose,}$ 0.1 mM EDTA containing EDTA-free protease inhibitor cocktail (Roche, 04693159001) and $0.2 \% 2$ mercaptoethanol) using a Teflon/glass homogenizer (10 strokes). The homogenates were cleared by centrifugation (1000 $\mathrm{xg}$ for $10 \mathrm{~min}$ ), and the supernatants were centrifuged at $15,000 \times \mathrm{g}$ at $4^{\circ} \mathrm{C}$ for 30 min to pellet the synaptosomes ( $\mathrm{P} 2$ fraction). The synaptosomes were washed twice at $4^{\circ} \mathrm{C}$ in $1 \mathrm{~mL}$ of ice-cold oxygenated K-R (Kreb's-Ringer) solution (25 mM HEPES, pH 7.4, $118 \mathrm{mM} \mathrm{NaCl}, 4.8 \mathrm{mM} \mathrm{KCl}, 25$ $\mathrm{mM} \mathrm{NaHCO}, 1.3 \mathrm{mM} \mathrm{CaCl} 2,1.2 \mathrm{mM}$ MgSO4, $1.2 \mathrm{mM} \mathrm{KH2PO4,} 10 \mathrm{mM}$ glucose, $100 \mu \mathrm{M}$ ascorbic acid, EDTA-free protease inhibitor cocktail). The synaptosomes were then resuspended in $1 \mathrm{~mL}$ of $\mathrm{K}$-R solution, 
and the protein concentrations were determined by the BCA kit. Two hundred $\mu \mathrm{g}$ synaptosomes were incubated with $0.1 \mu \mathrm{M}$ of $A \beta 42$, rApoE3, rApoE4 or AB42+rApoE4 in $200 \mu \mathrm{L}$ oxygenated Kreb's-Ringer for $30 \mathrm{~min}$ at $37^{\circ} \mathrm{C}$ followed by incubation with $1 \mu \mathrm{M}$ A23187 (Santa Cruz Biotechnology, sc-3591), $5 \mathrm{ng} / \mathrm{mL}$ $\mathrm{TNFa}+10 \mathrm{ng} / \mathrm{mL}$ IFN囚 or $2.5 \mu \mathrm{M}$ ceramide-1-phosphate (Sigma, C4832) for 15 min (oxygenated with 95\% 02/5\% CO2 for $1 \mathrm{~min}$ every $10 \mathrm{~min}$ ). Upon completion of incubation, an ice-cold protein phosphatase inhibitor cocktail (Roche, 04906837001) is added and placed on ice for $5 \mathrm{~min}$, and synaptosomes were pelleted by centrifugation.

The cytosolic and membranous fractions of the synaptosomes were prepared as established previously with minor modifications [60]. The synaptosomes were briefly sonicated (Kontes Micro Cell Disrupter) in $250 \mu \mathrm{L}$ of immunoprecipitation buffer $(25 \mathrm{mM}$ HEPES, pH 7.5, $200 \mathrm{mM} \mathrm{NaCl}, 1 \mathrm{mM}$ EDTA, protease and protein phosphatase inhibitor cocktails, and $0.02 \% 2$-mercaptoethanol and centrifuged at $48,000 \mathrm{x} \mathrm{g}$ for $15 \mathrm{~min}$. The resultant supernatant was removed as the cytosolic fraction, and the pellet was briefly sonicated in $200 \mu \mathrm{L}$ immunoprecipitation buffer as the membranous fraction. Both cytosolic and membranous fractions were solubilized with $0.5 \%$ digitonin, $0.2 \%$ sodium cholate, and $0.5 \% \mathrm{NP}-40$ (total incubation volume was $220 \mu \mathrm{L}$ and incubated at $4^{\circ} \mathrm{C}$ with end-to-end shaking for $1 \mathrm{~h}$. After dilution with $780 \mu \mathrm{L}$ of ice-cold immunoprecipitation buffer and centrifugation $\left(4^{\circ} \mathrm{C}\right)$ to remove insoluble debris. cPLA2 were isolated by immunoprecipitation with $16 \mathrm{~h}$ incubation at $4^{\circ} \mathrm{C}$ with anti-cPLA2 antibodies (Santa Cruz Biotechnology, sc-376618, and sc-137069) and protein A/G-conjugated agarose beads (Thermo Fisher, 20432). The resultant immunocomplexes were pelleted by centrifugation at $4^{\circ} \mathrm{C}$. After three washes with $1 \mathrm{~mL}$ of ice-cold PBS, pH 7.2, and centrifugation, the isolated cPLA2 was eluted with $90 \mu \mathrm{l} \mathrm{IgG} \mathrm{elution} \mathrm{buffer} \mathrm{(Thermo} \mathrm{Fisher,} \mathrm{21004),} \mathrm{neutralized} \mathrm{by} 10 \mu \mathrm{L} 1.5 \mathrm{M}$ Tris- $\mathrm{HCl}(\mathrm{pH} 9.0)$ and then solubilized by boiling for 5 min with $17 \mu \mathrm{L}$ of 6 X SDS-PAGE sample preparation buffer. The contents of activated cPLA2 ( $\mathrm{p}$-cPLA2) and total CPLA2 in $50 \%$ of the obtained anti-cPLA2 immunoprecipitants were determined respectively by Western-blot with anti-phosphorylated cPLA2 (Cell Signaling Technologies, 53044) and anti-cPLA2 (Santa Cruz Biotechnology, sc-376618) antibodies.

\section{Statistical analysis}

Descriptive results are presented as the mean \pm SD. Data were analyzed using Student's unpaired t-test or ANOVA. The CPLA2 phosphorylation was compared in APOE groups using a linear regression model, adjusting for age, sex, and Braak stage. Non-parametric tests were used for non-normally distributed data. Statistical significance was present at $p<0.05$. Statistical program $R$, version 3.5 was used. Quantification of WB gels was conducted on three independent experiments.

\section{Abbreviations}

ApoE, Apolipoprotein E; ApoE-TR, ApoE-targeted replacement; AD, Alzheimer disease; $\mathrm{NCl}$, no cognitive impairment; cPLA2, calcium-dependent cytosolic phospholipase A2; iPLA2, calcium-independent phospholipase A2 (iPLA2); DHA, docosahexaenoic acid; AA, arachidonic acid; LPC, lysophosphatidylcholine; LTB4, leukotriene B4; PGE2, prostaglandin E2; ROS, reactive oxygen species; 
iNOS, inducible nitric oxide synthase; NO, nitric oxide; COX, cyclooxygenase; LOX, lipoxygenase; MAPK, mitogen-activated protein kinase; MAVS, mitochondrial antiviral-signaling protein; NF-kB; nuclear factor kappa-light-chain-enhancer of activated B cells; LPS, lipopolysaccharide; CRP, C reactive protein.

\section{Declarations}

\section{Ethics approval and consent to participate}

The frozen hippocampus samples were collected from the University of Southern California (USC) Alzheimer Disease Research Center (ADRC) Neuropathology core, which was approved by USC's Institutional Review Board (IRB) protocol (HS-16-00888). The frozen inferior frontal lobe (Brodmann area 10) were obtained from the Rush Alzheimer's Disease Center (RADC) at the Rush University Medical Center. Rush Memory and Aging Project was approved by an Institutional Review Board (IRB) of Rush University Medical Center.

The USC Animal Care Committee approved the mouse studies.

\section{Consent for publication}

Not applicable.

\section{Availability of data and materials}

All data used and analyzed for the current study are available from the corresponding author on reasonable request.

\section{Competing interests}

The authors declare that they have no competing interests.

\section{Funding}

HNY was supported by R21AG056518, R01AG055770, R01AG054434, R01AG067063 from the National Institute on Aging and the Vranos Foundation. This work was also supported by P50AG05142 (HCC), P30 AG10161 (DAB), R01 AG17917 (DAB), R01 NS084965 (ZA), and RF1 AG059621 (ZA) from the National Institutes of Health. The contribution of SIR was funded by the Intramural Program of the National Institute on Alcohol Abuse and Alcoholism. Funders had no role in study design, data collection, data analysis, interpretation, or writing of the report.

\section{Authors' contributions}

HNY and SW designed experiments. SW and BL performed experiments. SW wrote the manuscript. PMS supplied mice. DAB and ZA supplied human cortex samples. HCC and CM supplied human hippocampus 
samples. HYW conducted the synaptosome experiments. VS, AF, SIR, DAB, ZA, HC, CM, HWY and HNY revised manuscript.

\section{Acknowledgments}

We thank Dr. Caleb Finch for critically reviewing the manuscript. We thank Dr. David M. Holtzman for providing us with ApoE3 and ApoE4 immortalized astrocytes.

\section{References}

1. Six DA, Dennis EA: The expanding superfamily of phospholipase $A 2$ enzymes: classification and characterization. Biochimica et Biophysica Acta (BBA)-Molecular and Cell Biology of Lipids 2000, 1488:1-19.

2. Strokin M, Sergeeva M, Reiser G: Docosahexaenoic acid and arachidonic acid release in rat brain astrocytes is mediated by two separate isoforms of phospholipase A2 and is differently regulated by cyclic AMP and Ca2+. Br J Pharmacol 2003, 139:1014-1022.

3. Cheon Y, Kim H-W, Igarashi M, Modi HR, Chang L, Ma K, Greenstein D, Wohltmann M, Turk J, Rapoport SI: Disturbed brain phospholipid and docosahexaenoic acid metabolism in calcium-independent phospholipase A2-VIA (iPLA2 $\beta$ )-knockout mice. Biochimica et Biophysica Acta (BBA)-Molecular and Cell Biology of Lipids 2012, 1821:1278-1286.

4. Gijón MA, Leslie CC: Regulation of arachidonic acid release and cytosolic phospholipase A2 activation. Journal of leukocyte biology 1999, 65:330-336.

5. Berk P, Stump D: Mechanisms of cellular uptake of long chain free fatty acids. In Lipid Binding Proteins within Molecular and Cellular Biochemistry. Springer; 1999: 17-31

6. Leslie CC: Cytosolic phospholipase A2: physiological function and role in disease. Journal of lipid research 2015, 56:1386-1402.

7. Chao CC, Gutierrez-Vazquez C, Rothhammer V, Mayo L, Wheeler MA, Tjon EC, Zandee SEJ, Blain M, de Lima KA, Takenaka MC, et al: Metabolic Control of Astrocyte Pathogenic Activity via cPLA2-MAVS. Cell 2019, 179:1483-1498 e1422.

8. Chuang DY, Simonyi A, Kotzbauer PT, Gu Z, Sun GY: Cytosolic phospholipase A 2 plays a crucial role in ROS/NO signaling during microglial activation through the lipoxygenase pathway. Journal of neuroinflammation 2015, 12:199.

9. Lin L-L, Wartmann M, Lin AY, Knopf JL, Seth A, Davis RJ: cPLA2 is phosphorylated and activated by MAP kinase. Cell 1993, 72:269-278.

10. Xu J, Weng Y-I, Simonyi A, Krugh BW, Liao Z, Weisman GA, Sun GY: Role of PKC and MAPK in cytosolic PLA2 phosphorylation and arachadonic acid release in primary murine astrocytes. $J$ Neurochem 2002, 83:259-270.

11. Perez-Nievas BG, Stein TD, Tai H-C, Dols-Icardo O, Scotton TC, Barroeta-Espar I, Fernandez-Carballo L, De Munain EL, Perez J, Marquie M: Dissecting phenotypic traits linked to human resilience to 
Alzheimer's pathology. Brain 2013, 136:2510-2526.

12. Stephenson DT, Lemere CA, Selkoe DJ, Clemens JA: Cytosolic phospholipase A2 (cPLA2) immunoreactivity is elevated in Alzheimer's disease brain. Neurobiology of disease 1996, 3:51-63.

13. Colangelo V, Schurr J, Ball MJ, Pelaez RP, Bazan NG, Lukiw WJ: Gene expression profiling of 12633 genes in Alzheimer hippocampal CA1: transcription and neurotrophic factor down-regulation and upregulation of apoptotic and pro-inflammatory signaling. Journal of neuroscience research 2002, 70:462-473.

14. Sanchez-Mejia RO, Newman JW, Toh S, Yu GQ, Zhou Y, Halabisky B, Cisse M, Scearce-Levie K, Cheng $\mathrm{IH}, \mathrm{Gan} \mathrm{L}$, et al: Phospholipase $\mathrm{A} 2$ reduction ameliorates cognitive deficits in a mouse model of Alzheimer's disease. Nat Neurosci 2008, 11:1311-1318.

15. Sun GY, He Y, Chuang DY, Lee JC, Gu Z, Simonyi A, Sun AY: Integrating cytosolic phospholipase A 2 with oxidative/nitrosative signaling pathways in neurons: a novel therapeutic strategy for AD. Molecular neurobiology 2012, 46:85-95.

16. Palavicini JP, Wang C, Chen L, Hosang K, Wang J, Tomiyama T, Mori H, Han X: Oligomeric amyloidbeta induces MAPK-mediated activation of brain cytosolic and calcium-independent phospholipase A 2 in a spatial-specific manner. Acta neuropathologica communications 2017, 5:56.

17. Sundaram JR, Chan ES, Poore CP, Pareek TK, Cheong WF, Shui G, Tang N, Low C-M, Wenk MR, Kesavapany S: Cdk5/p25-induced cytosolic PLA2-mediated lysophosphatidylcholine production regulates neuroinflammation and triggers neurodegeneration. Journal of Neuroscience 2012, 32:1020-1034.

18. Qu B, Gong Y, Gill JM, Kenney K, Diaz-Arrastia R: Heterozygous knockout of cytosolic phospholipase A2 $a$ attenuates Alzheimer's disease pathology in APP/PS1 transgenic mice. Brain research 2017, 1670:248-252.

19. Tao Q, Ang TFA, DeCarli C, Auerbach SH, Devine S, Stein TD, Zhang X, Massaro J, Au R, Qiu WQ: Association of Chronic Low-grade Inflammation With Risk of Alzheimer Disease in ApoE4 Carriers. JAMA Netw Open 2018, 1:e183597.

20. Ramassamy C, Averill D, Beffert U, Theroux L, Lussier-Cacan S, Cohn JS, Christen Y, Schoofs A, Davignon J, Poirier J: Oxidative insults are associated with apolipoprotein E genotype in Alzheimer's disease brain. Neurobiology of disease 2000, 7:23-37.

21. Tomaszewski N, He X, Solomon V, Lee M, Mack WJ, Quinn JF, Braskie MN, Yassine HN: Effect of APOE Genotype on Plasma Docosahexaenoic Acid (DHA), Eicosapentaenoic Acid, Arachidonic Acid, and Hippocampal Volume in the Alzheimer's Disease Cooperative Study-Sponsored DHA Clinical Trial. J Alzheimers Dis 2020, 74:975-990.

22. Yassine HN RV, Mack WJ, Quinn JF, Yurko-Mauro K, Bailey-Hall E, Aisen PS, Chui HC, Schneider LS: The effect of APOE genotype on the delivery of DHA to cerebrospinal fluid in Alzheimer's disease. Alzheimer's Reaserch and Therapy 2016, 8:25.

23. Moore SA: Polyunsaturated fatty acid synthesis and release by brain-derived cells in vitro. Journal of Molecular Neuroscience 2001, 16:195-200. 
24. Kramer RM, Roberts EF, Um SL, Borsch-Haubold AG, Watson SP, Fisher MJ, Jakubowski JA: p38 mitogen-activated protein kinase phosphorylates cytosolic phospholipase A2 (cPLA2) in thrombinstimulated platelets. Evidence that proline-directed phosphorylation is not required for mobilization of arachidonic acid by cPLA2. J Biol Chem 1996, 271:27723-27729.

25. Yun B, Lee H, Jayaraja S, Suram S, Murphy RC, Leslie CC: Prostaglandins from Cytosolic Phospholipase A2a/Cyclooxygenase-1 Pathway and Mitogen-activated Protein Kinases Regulate Gene Expression in Candida albicans-infected Macrophages. The Journal of biological chemistry 2016, 291:7070-7086.

26. Kumar S, Jiang MS, Adams JL, Lee JC: Pyridinylimidazole compound SB 203580 inhibits the activity but not the activation of p38 mitogen-activated protein kinase. Biochemical and biophysical research communications 1999, 263:825-831.

27. Bate $C$, Williams A: Monomeric amyloid- $\beta$ reduced amyloid- $\beta$ oligomer-induced synapse damage in neuronal cultures. Neurobiology of disease 2018, 111:48-58.

28. Vitek MP, Brown CM, Colton CA: APOE genotype-specific differences in the innate immune response. Neurobiol Aging 2009, 30:1350-1360.

29. Colton CA, Brown CM, Cook D, Needham LK, Xu Q, Czapiga M, Saunders AM, Schmechel DE, Rasheed $\mathrm{K}$, Vitek MP: APOE and the regulation of microglial nitric oxide production: a link between genetic risk and oxidative stress. Neurobiology of aging 2002, 23:777-785.

30. Guo L, LaDu MJ, Van Eldik LJ: A dual role for apolipoprotein e in neuroinflammation: anti- and proinflammatory activity. J Mol Neurosci 2004, 23:205-212.

31. Chen S, Averett NT, Manelli A, Ladu MJ, May W, Ard MD: Isoform-specific effects of apolipoprotein E on secretion of inflammatory mediators in adult rat microglia. $J$ Alzheimers Dis 2005, 7:25-35.

32. Shi Y, Yamada K, Liddelow SA, Smith ST, Zhao L, Luo W, Tsai RM, Spina S, Grinberg LT, Rojas JC, et al: ApoE4 markedly exacerbates tau-mediated neurodegeneration in a mouse model of tauopathy. Nature 2017, 549:523-527.

33. Tai LM, Balu D, Avila-Munoz E, Abdullah L, Thomas R, Collins N, Valencia-Olvera AC, LaDu MJ: EFAD transgenic mice as a human APOE relevant preclinical model of Alzheimer's disease. Journal of lipid research 2017, 58:1733-1755.

34. Zhu Y, Nwabuisi-Heath E, Dumanis SB, Tai LM, Yu C, Rebeck GW, Ladu MJ: APOE genotype alters glial activation and loss of synaptic markers in mice. Glia 2012, 60:559-569.

35. Ophir G, Amariglio N, Jacob-Hirsch J, Elkon R, Rechavi G, Michaelson DM: Apolipoprotein E4 enhances brain inflammation by modulation of the NF-KB signaling cascade. Neurobiology of disease 2005, 20:709-718.

36. Gale SC, Gao L, Mikacenic C, Coyle SM, Rafaels N, Dudenkov TM, Madenspacher JH, Draper DW, Ge $\mathrm{W}$, Aloor $\mathrm{JJ}$ : APOع4 is associated with enhanced in vivo innate immune responses in human subjects. Journal of allergy and clinical immunology 2014, 134:127-134. e129.

37. Montine KS, Olson SJ, Amarnath V, Whetsell WO, Jr., Graham DG, Montine TJ: Immunohistochemical detection of 4-hydroxy-2-nonenal adducts in Alzheimer's disease is associated with inheritance of 
APOE4. Am J Pathol 1997, 150:437-443.

38. Egensperger R, Kösel S, von Eitzen U, Graeber MB: Microglial activation in Alzheimer disease: association with APOE genotype. Brain Pathology 1998, 8:439-447.

39. Minett T, Classey J, Matthews FE, Fahrenhold M, Taga M, Brayne C, Ince PG, Nicoll JA, Boche D, CFAS M: Microglial immunophenotype in dementia with Alzheimer's pathology. Journal of neuroinflammation 2016, 13:135.

40. Friedberg JS, Aytan N, Cherry JD, Xia W, Standring OJ, Alvarez VE, Nicks R, Svirsky S, Meng G, Jun G: Associations between brain inflammatory profiles and human neuropathology are altered based on apolipoprotein E $\varepsilon 4$ genotype. Scientific Reports 2020, 10:1-10.

41. Fonteh AN, Chiang J, Cipolla M, Hale J, Diallo F, Chirino A, Arakaki X, Harrington MG: Alterations in cerebrospinal fluid glycerophospholipids and phospholipase A2 activity in Alzheimer's disease. Journal of lipid research 2013, 54:2884-2897.

42. Esposito G, Giovacchini G, Liow JS, Bhattacharjee AK, Greenstein D, Schapiro M, Hallett M, Herscovitch P, Eckelman WC, Carson RE, Rapoport SI: Imaging neuroinflammation in Alzheimer's disease with radiolabeled arachidonic acid and PET. Journal of nuclear medicine : official publication, Society of Nuclear Medicine 2008, 49:1414-1421.

43. Abdullah L, Evans JE, Emmerich T, Crynen G, Shackleton B, Keegan AP, Luis C, Tai L, LaDu MJ, Mullan M: APOE \&4 specific imbalance of arachidonic acid and docosahexaenoic acid in serum phospholipids identifies individuals with preclinical Mild Cognitive Impairment/Alzheimer's Disease. Aging (Albany NY) 2017, 9:964.

44. Gentile MT, Reccia M, Sorrentino P, Vitale E, Sorrentino G, Puca A, Colucci-D'Amato L: Role of cytosolic calcium-dependent phospholipase A2 in Alzheimer's disease pathogenesis. Molecular neurobiology 2012, 45:596-604.

45. Osborne C, West E, Bate C: The phospholipase A2 pathway controls a synaptic cholesterol ester cycle and synapse damage. J Cell Sci 2018, 131:jcs211789.

46. Desbène $C$, Malaplate-Armand $C$, Youssef I, Garcia P, Stenger C, Sauvée M, Fischer N, Rimet D, Koziel $\mathrm{V}$, Escanyé M-C: Critical role of CPLA2 in A $\beta$ oligomer-induced neurodegeneration and memory deficit. Neurobiology of aging 2012, 33:1123. e1117-1123. e1129.

47. Last V, Williams A, Werling D: Inhibition of cytosolic phospholipase A 2 prevents prion peptideinduced neuronal damage and co-localisation with beta III tubulin. BMC neuroscience 2012, 13:106.

48. Sanchez-Mejia RO: Phospholipase A2 reduction ameliorates cognitive deficits in a mouse model of Alzheimer's disease. Nat Neurosci 2008, 11.

49. Zhao N, Ren Y, Yamazaki Y, Qiao W, Li F, Felton LM, Mahmoudiandehkordi S, Kueider-Paisley A, Sonoustoun B, Arnold M, et al: Alzheimer's Risk Factors Age, APOE Genotype, and Sex Drive Distinct Molecular Pathways. Neuron 2020, 106:727-742.e726.

50. Soubhye J, van Antwerpen P, Dufrasne F: Targeting Cytosolic Phospholipase A2alpha for Novel AntiInflammatory Agents. Curr Med Chem 2018, 25:2418-2447. 
51. Koundouros N, Karali E, Tripp A, Valle A, Inglese P, Perry NJ, Magee DJ, Virmouni SA, Elder GA, Tyson AL: Metabolic Fingerprinting Links Oncogenic PIK3CA with Enhanced Arachidonic Acid-Derived Eicosanoids. Cell 2020.

52. Vezzani A, Balosso S, Ravizza T: Neuroinflammatory pathways as treatment targets and biomarkers in epilepsy. Nature Reviews Neurology 2019, 15:459-472.

53. Huang YA, Zhou B, Wernig M, Sudhof TC: ApoE2, ApoE3, and ApoE4 Differentially Stimulate APP Transcription and Abeta Secretion. Cell 2017, 168:427-441.e421.

54. Salomon-Zimri S, Koren A, Angel A, Ben-Zur T, Offen D, Michaelson DM: The Role of MAPK's Signaling in Mediating ApoE4-Driven Pathology In Vivo. Current Alzheimer Research 2019, 16:281292.

55. Scheltens P, Prins N, Lammertsma A, Yaqub M, Gouw A, Wink AM, Chu H-M, van Berckel BNM, Alam $\mathrm{J}$ : An exploratory clinical study of p38a kinase inhibition in Alzheimer's disease. Ann Clin Trans/ Neurol 2018, 5:464-473.

56. Sullivan PM, Mezdour H, Aratani Y, Knouff C, Najib J, Reddick RL, Quarfordt SH, Maeda N: Targeted replacement of the mouse apolipoprotein E gene with the common human APOE3 allele enhances diet-induced hypercholesterolemia and atherosclerosis. J Biol Chem 1997, 272:17972-17980.

57. Simonovitch S, Schmukler E, Bespalko A, Iram T, Frenkel D, Holtzman DM, Masliah E, Michaelson DM, Pinkas-Kramarski R: Impaired Autophagy in APOE4 Astrocytes. J Alzheimers Dis 2016, 51:915-927.

58. Morikawa M, Fryer JD, Sullivan PM, Christopher EA, Wahrle SE, DeMattos RB, O'Dell MA, Fagan AM, Lashuel HA, Walz T, et al: Production and characterization of astrocyte-derived human apolipoprotein E isoforms from immortalized astrocytes and their interactions with amyloid-beta. Neurobiol Dis 2005, 19:66-76.

59. Wang H-Y, Stucky A, Liu J, Shen C, Trocme-Thibierge C, Morain P: Dissociating $\beta$-amyloid from a7 nicotinic acetylcholine receptor by a novel therapeutic agent, $S 24795$, normalizes a7 nicotinic acetylcholine and NMDA receptor function in Alzheimer's disease brain. Journal of Neuroscience 2009, 29:10961-10973.

60. Wang $\mathrm{H}-\mathrm{Y}$, Pisano MR, Friedman $\mathrm{E}$ : Attenuated protein kinase $\mathbf{C}$ activity and translocation in Alzheimer's disease brain. Neurobiology of aging 1994, 15:293-298.

\section{Figures}



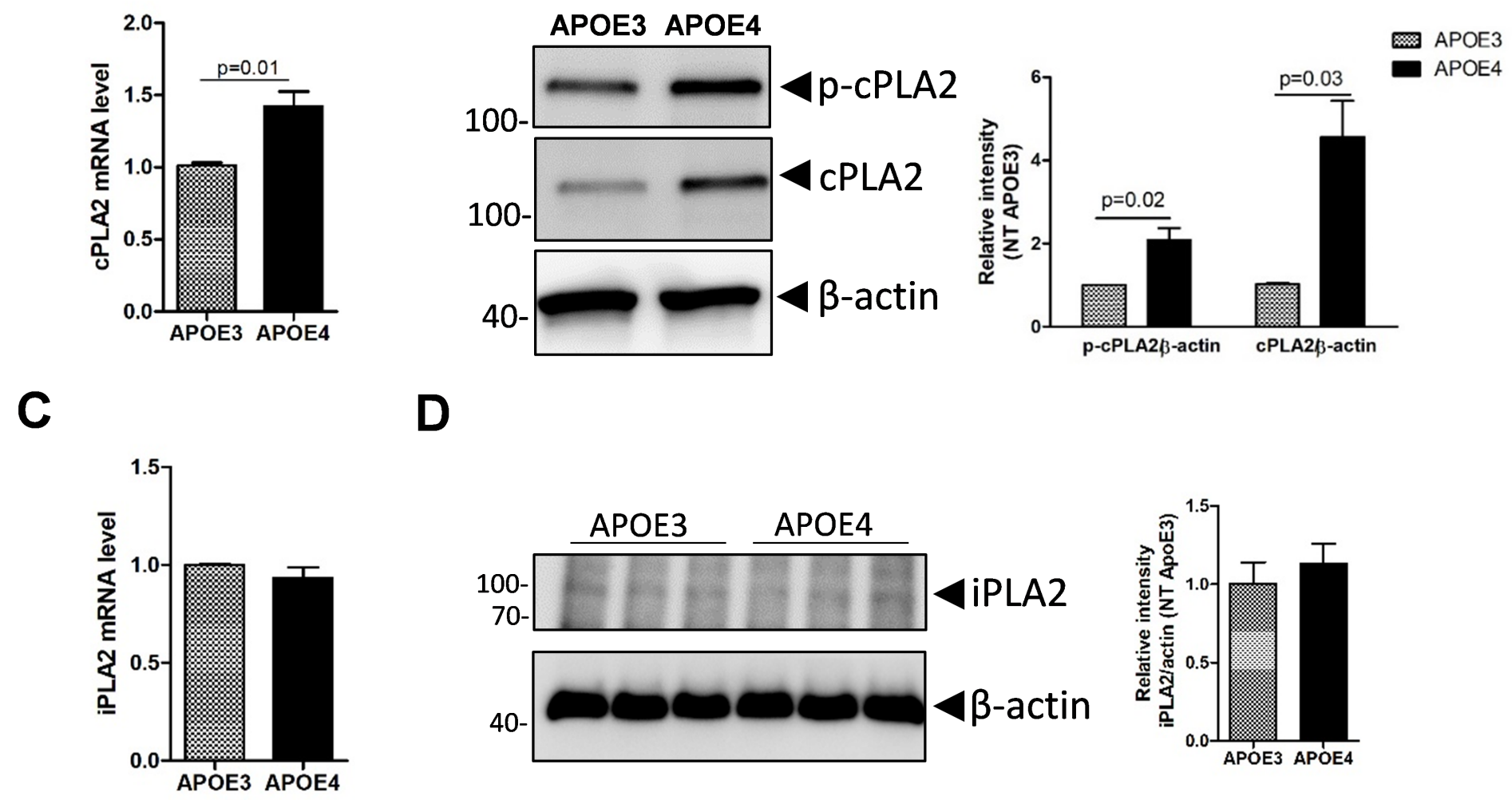

D
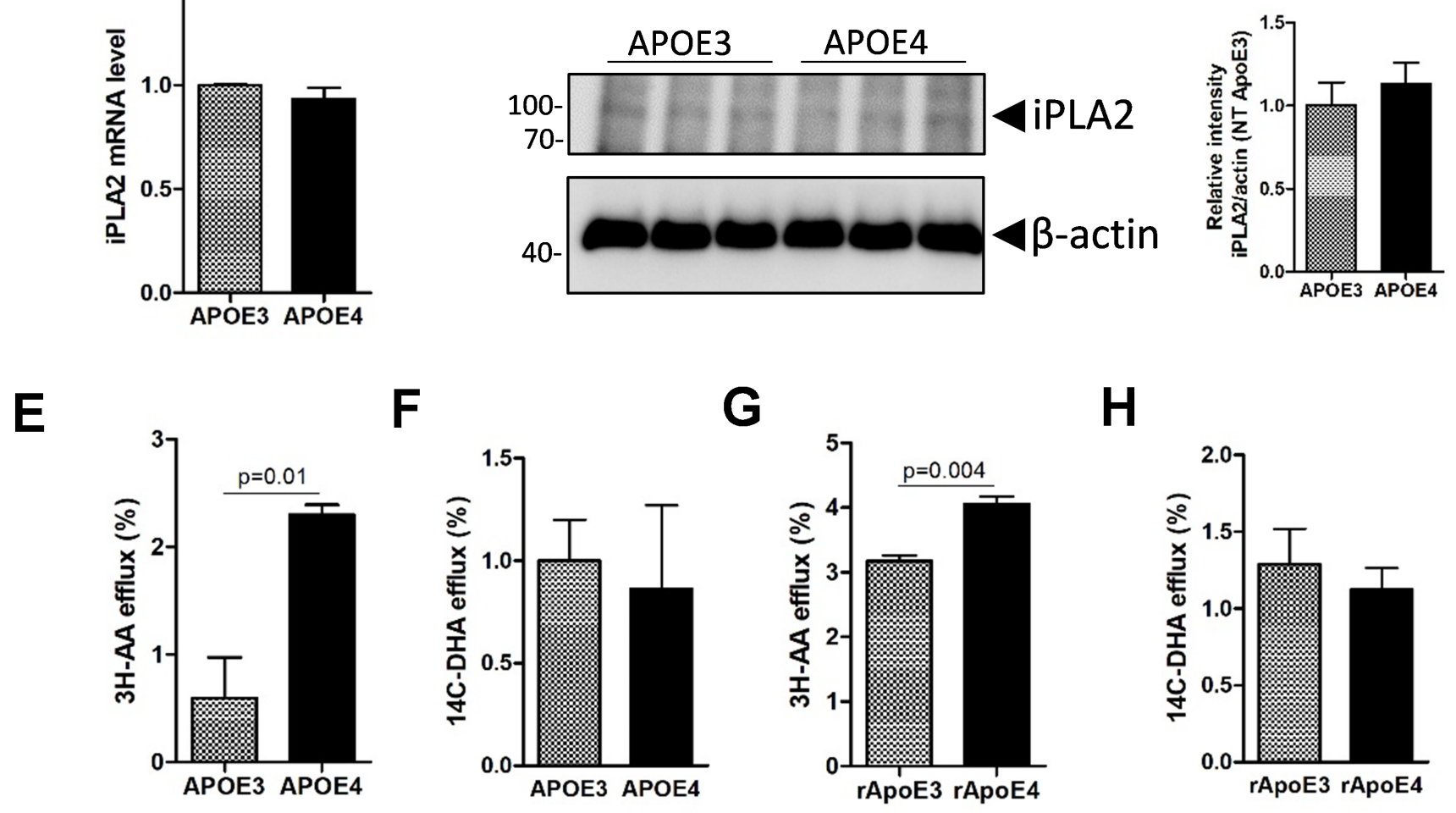

Figure 1

ApoE4 increases cPLA2 but not iPLA2 expression in mouse primary astrocytes. A. cPLA2 mRNA levels in primary astrocytes from APOE3 and APOE4-TR mice. B, cPLA2, and phosphorylated cPLA2 (p-cPLA2) protein levels in primary astrocytes from ApoE3 and ApoE4-TR mice (left) were detected WB. C, iPLA2 mRNA levels in primary astrocytes from ApoE3 and ApoE4-TR mice. D, iPLA2 protein levels in primary astrocyte cultures from ApoE3 and ApoE4-TR mice was detected by WB. E, F, Primary astrocytes from ApoE3 and ApoE4-TR mice were incubated with 3H-labelled AA (E) or 14C-labeled DHA (F) for 24h, followed by induction by $100 \mathrm{nM}$ ATP for $15 \mathrm{~min}$. The efflux of 3H-AA (E) and 14C-DHA (F) from cells to media was measured by scintillation counting. $G, H$, Primary astrocytes from C57BL/ 6 wild type mice were labeled with $3 \mathrm{H}-\mathrm{AA}(\mathrm{G})$ or $14 \mathrm{C}-\mathrm{DHA}(\mathrm{H})$ for $24 \mathrm{~h}$ and then treated with recombinant ApoE3 or ApoE4 
for $24 \mathrm{~h}$, followed by induction with 100nM ATP for 15min. 3H-AA (G) and 14C-DHA (H) efflux were measured by scintillation counting. WB: western blot.
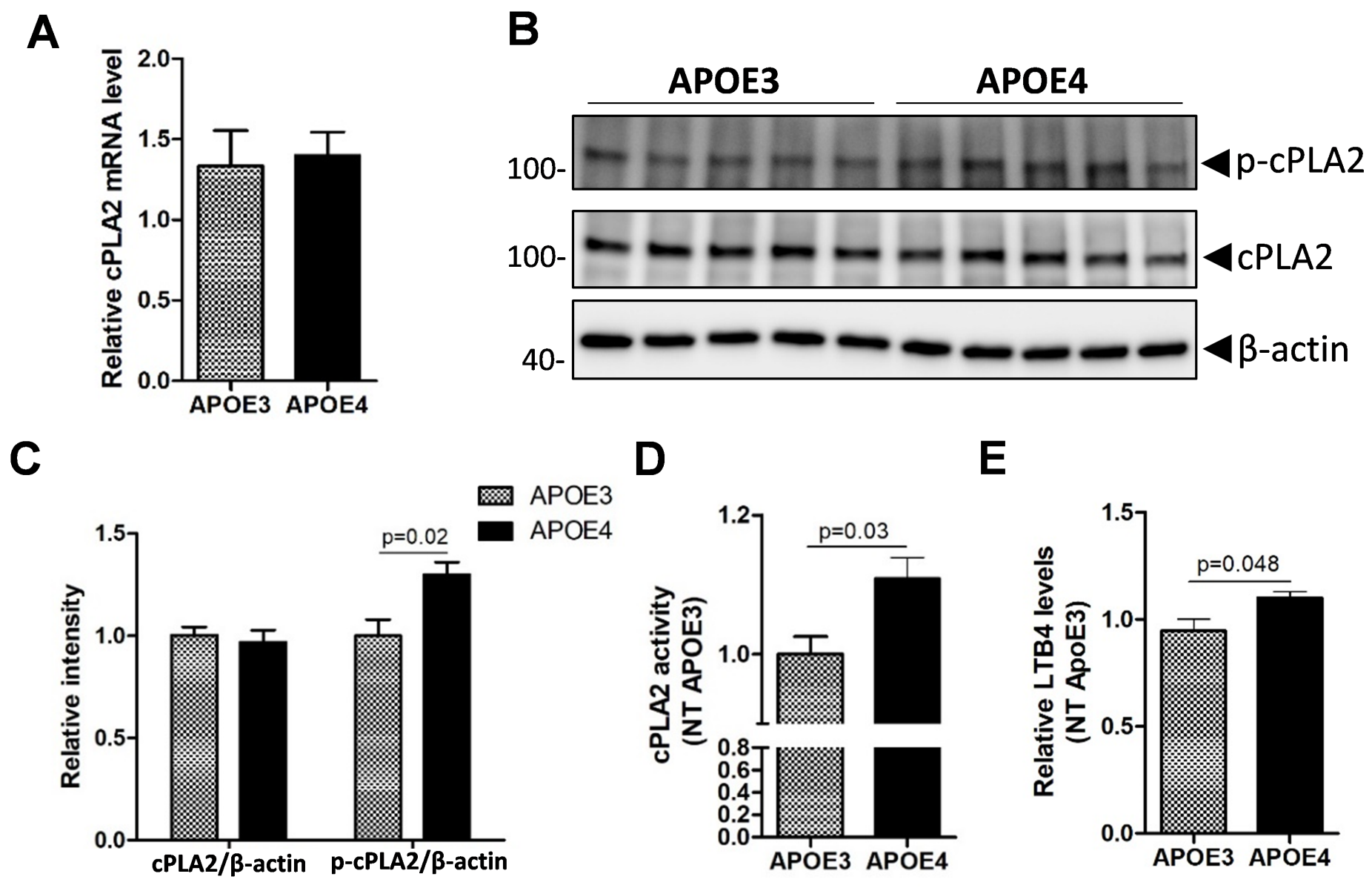

Figure 2

cPLA2 and phosphorylated-cPLA2 level in 8-month old ApoE3-TR and ApoE4-TR mouse brains. The cortex of 8-month old ApoE3 and ApoE4-TR mice were collected. A, cPLA2 mRNA level in the cortex was detected by qPCR. B, Phosphorylated-CPLA2 and total CPLA2 protein levels in the cortex were detected by western blot. C.Densitometric quantification from B. D, cPLA2 activity in mouse cortex homogenates were measured by CPLA2 activity assay kit. E, LTB4 levels in mouse cortical homogenates were measured by LTB4 assay kit. ( $n=5$ for each genotype, 3 males and 2 females). 
A
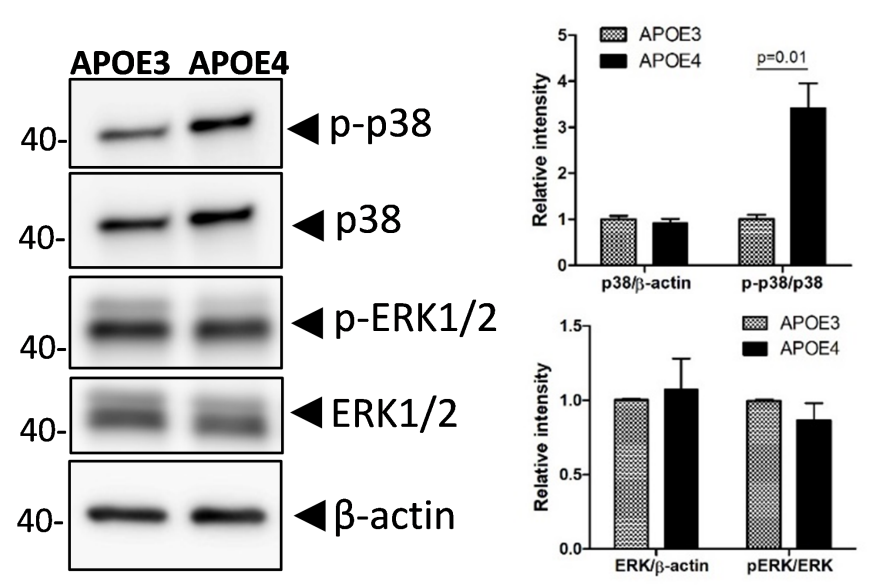

B
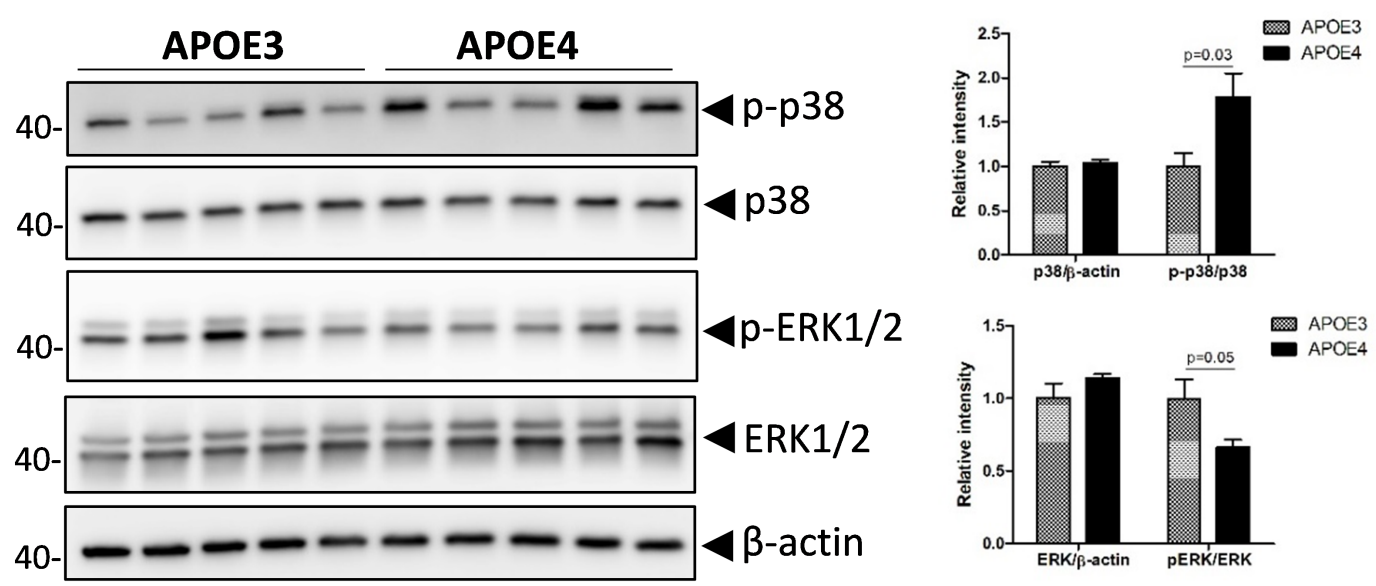

C
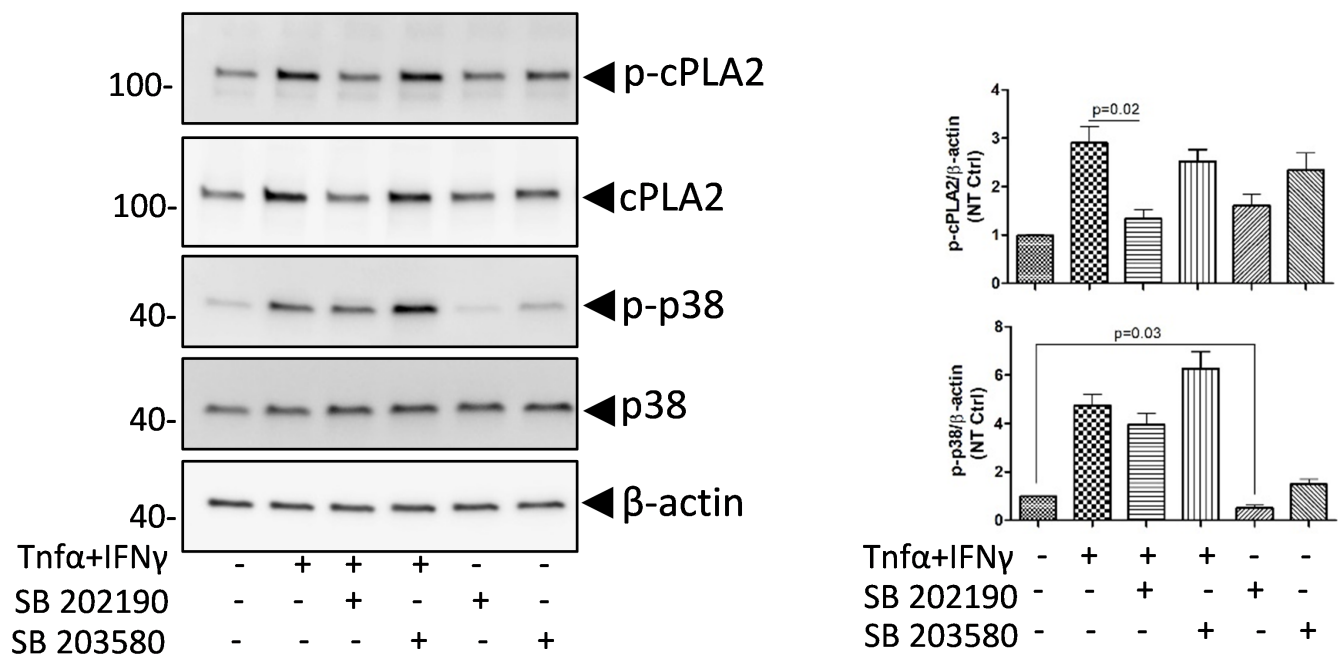

\section{Figure 3}

Increased phosphorylated-cPLA2 in APOE4 is mediated by p38 MAPK. A, Phosphorylated and total p38 and ERK levels in primary astrocyte from ApoE3 and ApoE4-TR mice were detected by WB. B, Phosphorylated and total p38 and ERK levels in cortical homogenates from APOE3 and APOE4-TR mice were detected by WB. C, ApoE4 primary astrocytes from mouse were pre-treated with p38 inhibitors SB $202190(10 \mu \mathrm{M})$ or SB $203580(10 \mu \mathrm{M})$ for 20 minutes and then treated with medium or TNFa plus IFNy 
together for 30 minutes. The total and phosphorylated cPLA2 and p38 were detected in the cell lysate by WB. D, CPLA2 bound with p38. Immunoprecipitation was performed in the cell lysate of immortalized ApoE4 astrocytes using anti-cPLA2 antibody or species-matched IgG. cPLA2 and p38 were co-detected after immunoprecipitation by WB. WB: Western Blot.

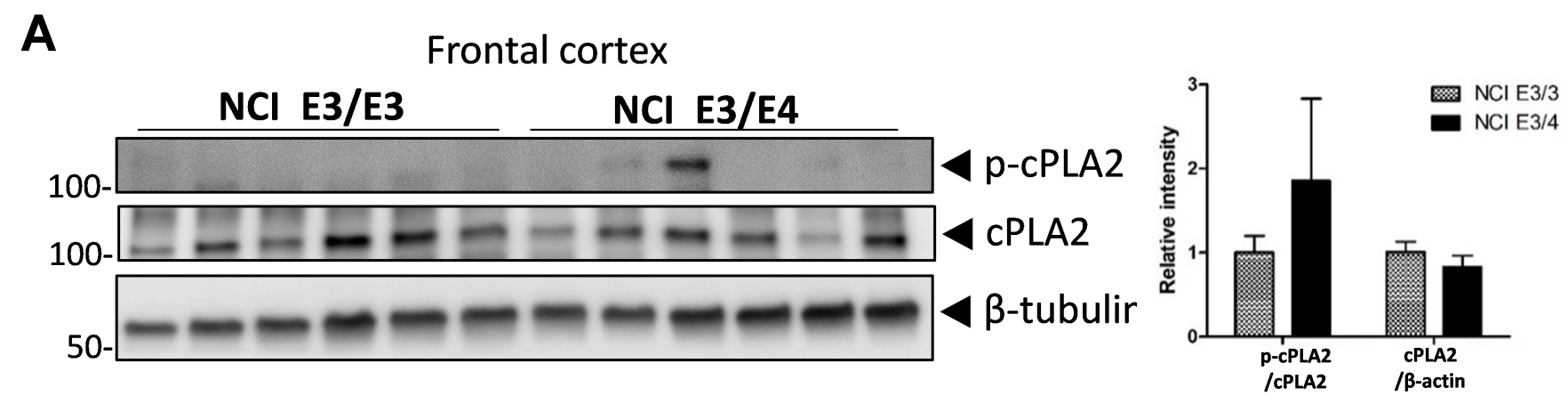

B

Frontal cortex
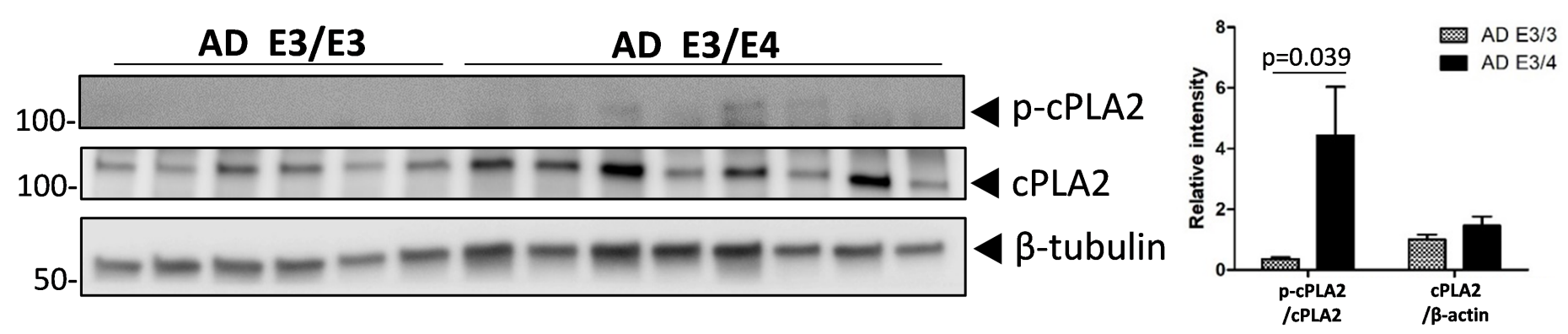

Figure 4

cPLA2 and phosphorylated-cPLA2 levels in the brains of persons with different APOE genotypes. A, pCPLA2, and CPLA2 protein levels in the inferior frontal cortex from persons with $\mathrm{NCl}$ were detected by WB (left). Densitometric quantification of the blotting (right). B, p-CPLA2, and CPLA2 protein levels in the inferior frontal cortex from AD patients were detected by WB. Densitometric quantification of the blotting (right). WB: Western Blot. 
A

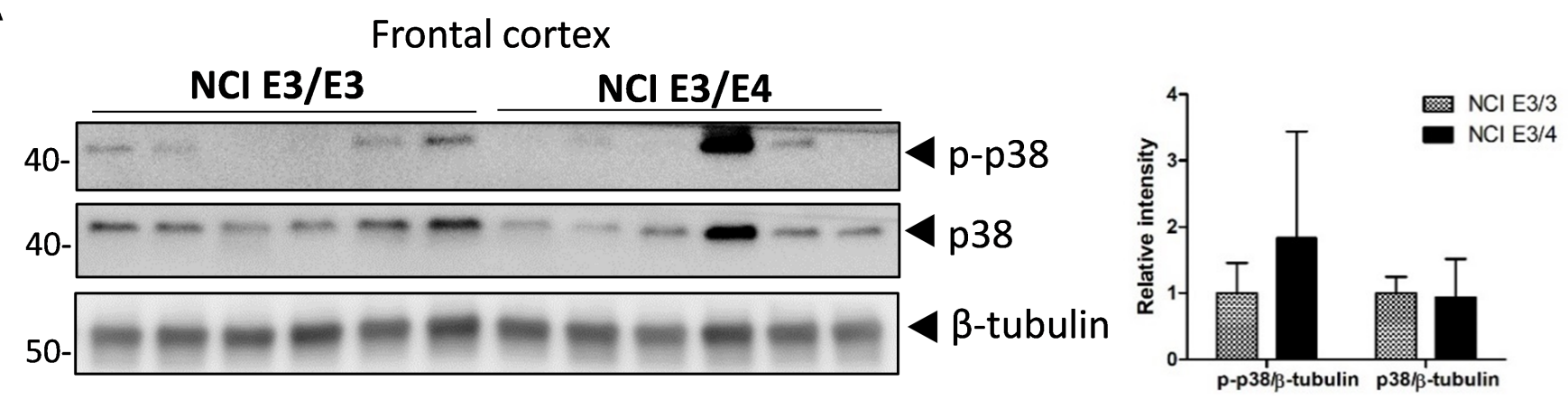

B

\section{Frontal cortex}
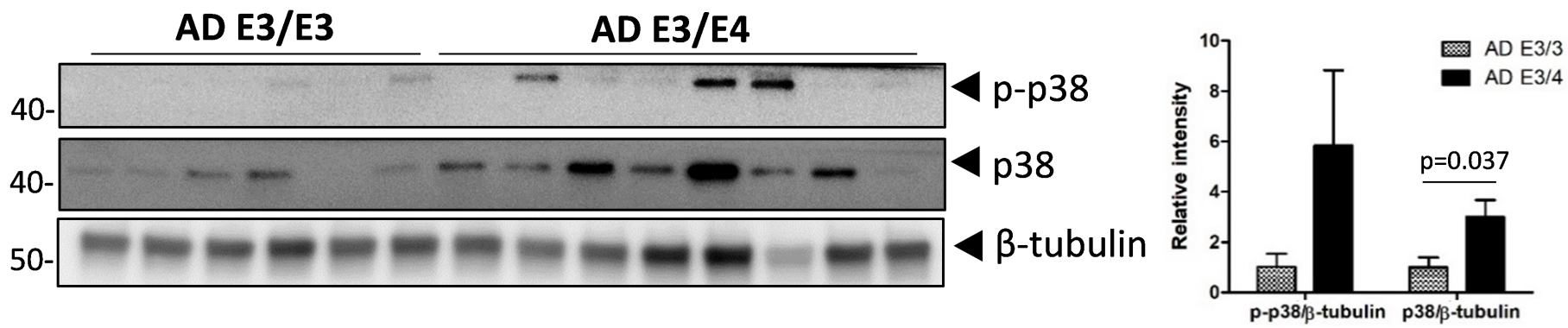

Figure 5

p38 levels in the brains of humans with different APOE genotypes. A, p-p38 and p38 protein levels in inferior frontal cortex from persons with $\mathrm{NCl}$ were detected by WB. Densitometric quantification of the blotting (right). B, p-p38 and p38 protein level in inferior frontal cortex from AD patients were detected by WB. Densitometric quantification of the blotting (right). WB: Western blot. 
A

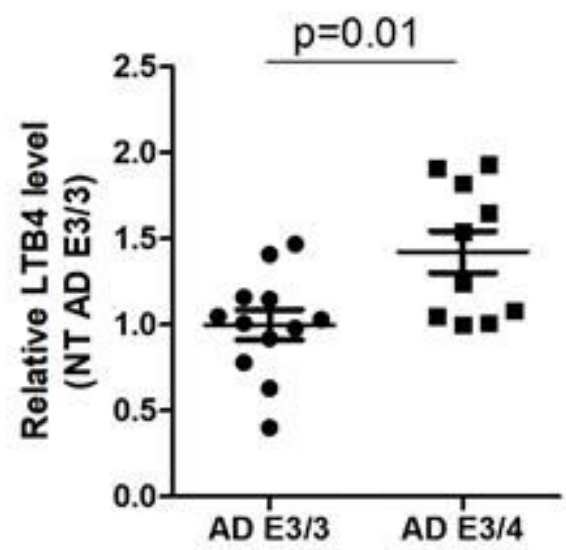

C

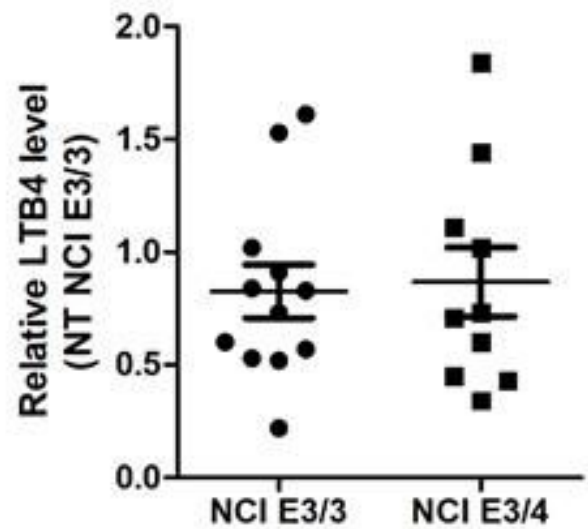

B

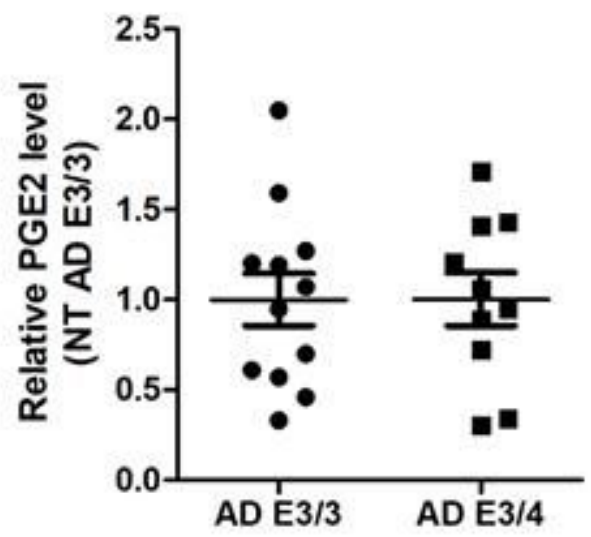

D

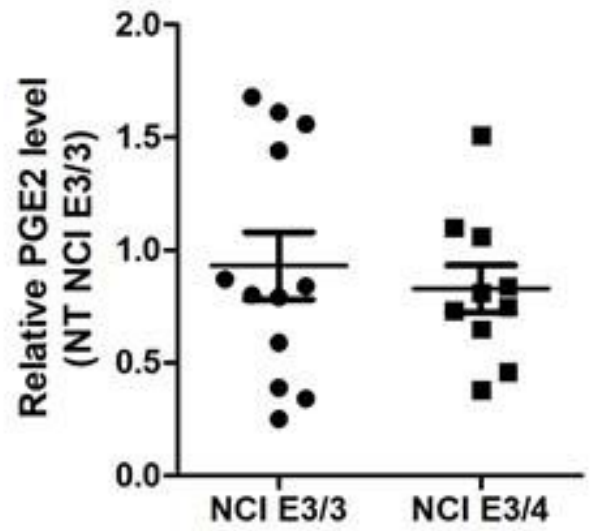

E
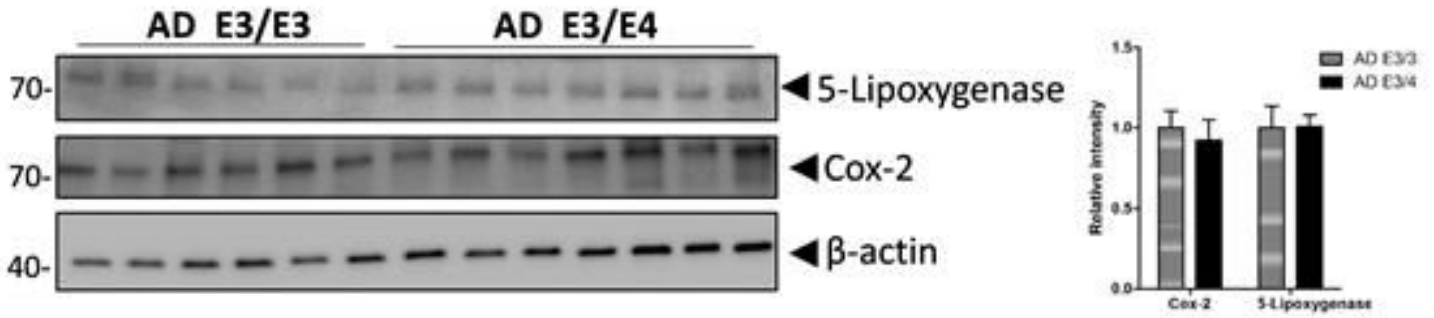

Figure 6

LTB4 and PGE2 levels in the cortex of humans with different APOE genotypes. LTB4 (A, C) and PGE2 (B, D) levels in the inferior frontal cortex of $A D$ patients $(A, B)$ and $N C l$ participants $(C, D)$ with different $A P O E$ genotypes. E, 5-Lipoxygenase and cyclooxygenase 2 protein levels in inferior frontal cortex from $A D$ patients were detected by WB. (n=12 (F6/M6) for NCI E3/E3; $n=10$ (F5/M5) for NCI E3/E4; n=12 (F5/M7) for $A D$ E3/E3; $n=10$ (F6/M4) for AD E3/E4). WB: Western blot. 
A

Primary astrocytes

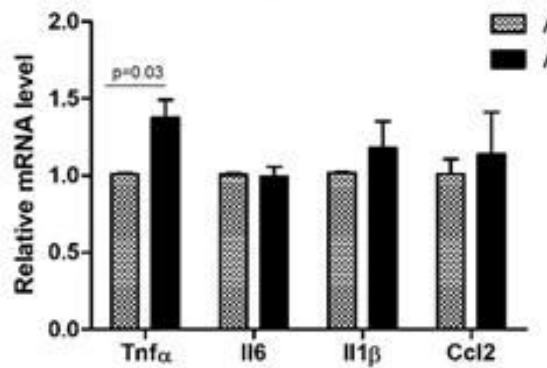

B

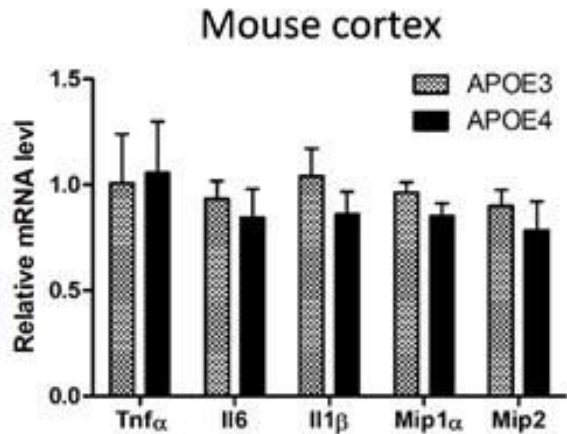

C

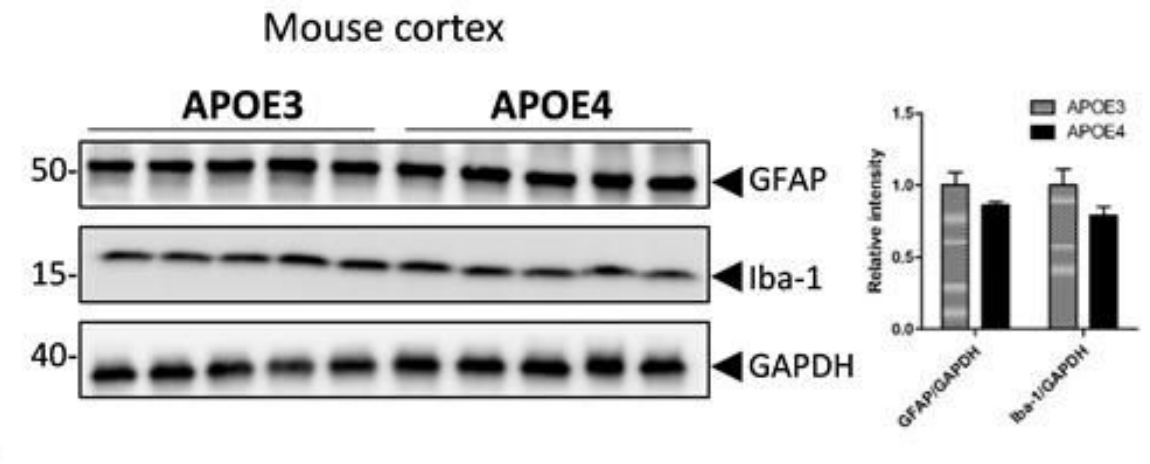

D $E$

Human cortex

Human cortex
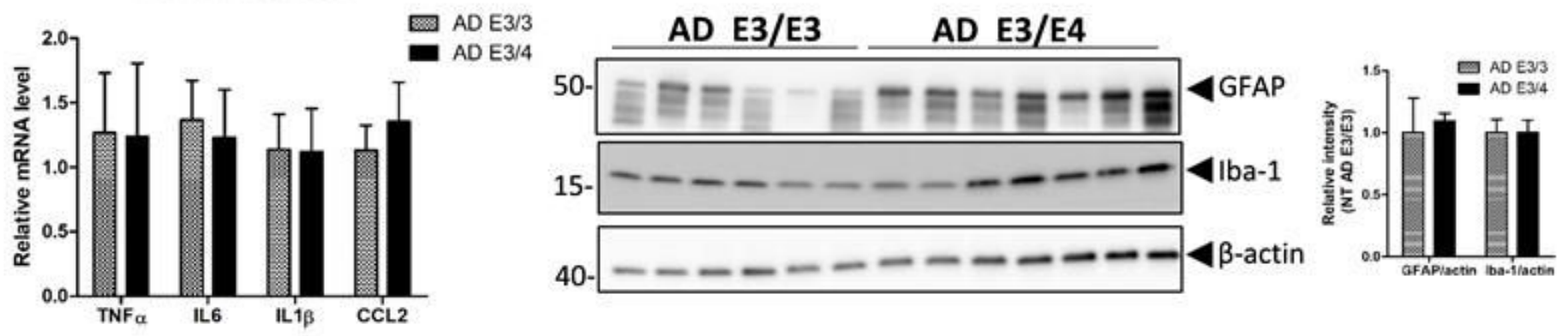

Figure 7

Inflammatory responses in primary astrocytes, mouse, and human cortex with different APOE genotypes. A, mRNA levels of proinflammatory markers in the primary astrocyte from ApoE3-TR or ApoE4-TR mice. B, mRNA levels of proinflammatory cytokines in the cortex of ApoE3-TR or ApoE4-TR mice. C, GFAP, and Iba1 expression in the cortex of ApoE3-TR or ApoE4-TR mice. ( $n=5,3$ males and 2 females for $B$ and C). $D$, mRNA levels of proinflammatory markers in inferior frontal cortex from AD patients. E, GFAP and Iba-1 expression in inferior frontal cortex from AD patients. ( $n=12$ (F5/M7) for $A D E 3 / E 3 ; n=10$ (F6/M4) for $A D$ E3/E4). 
A

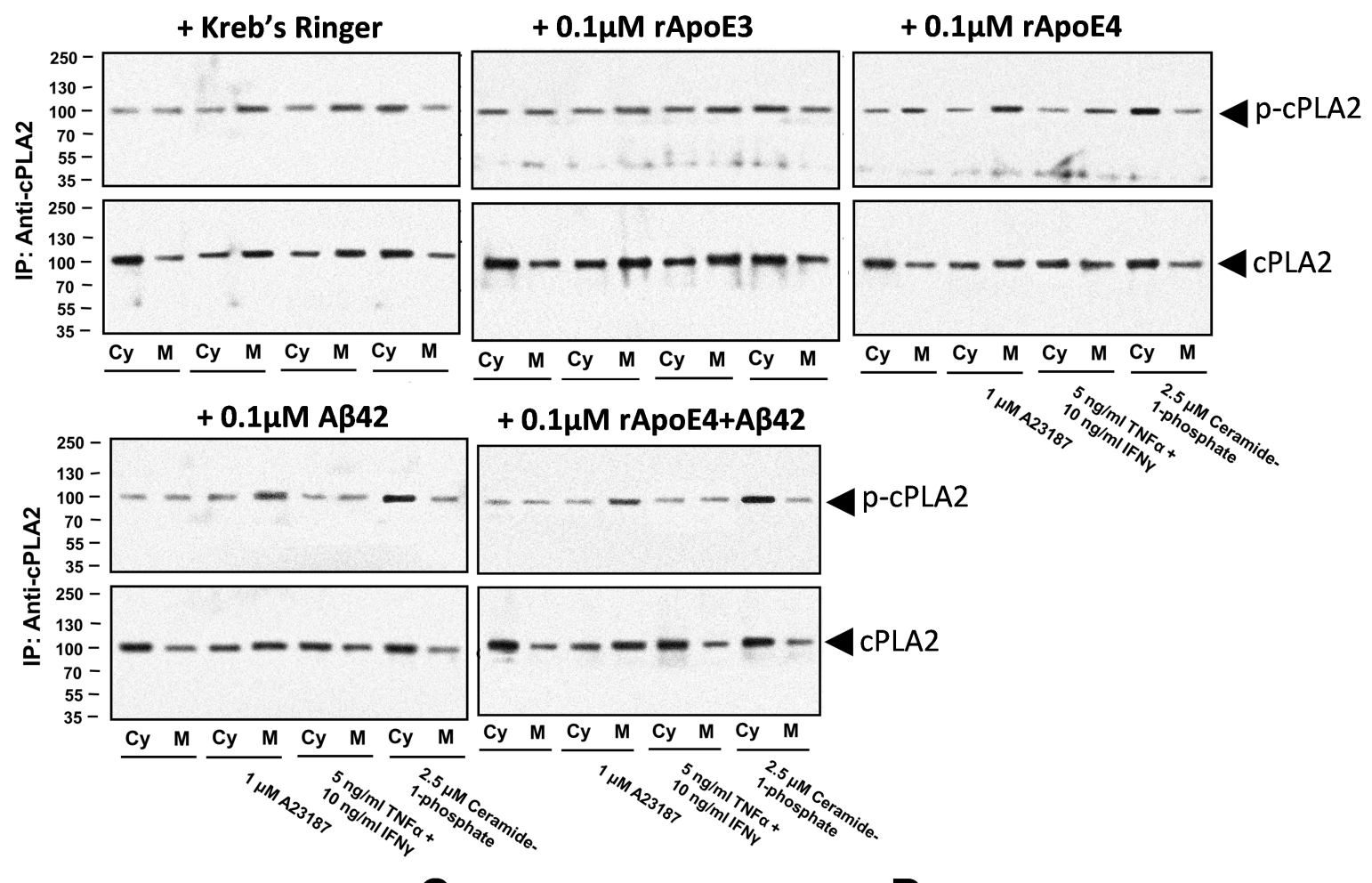

B

+ Kreb's Ringer

C
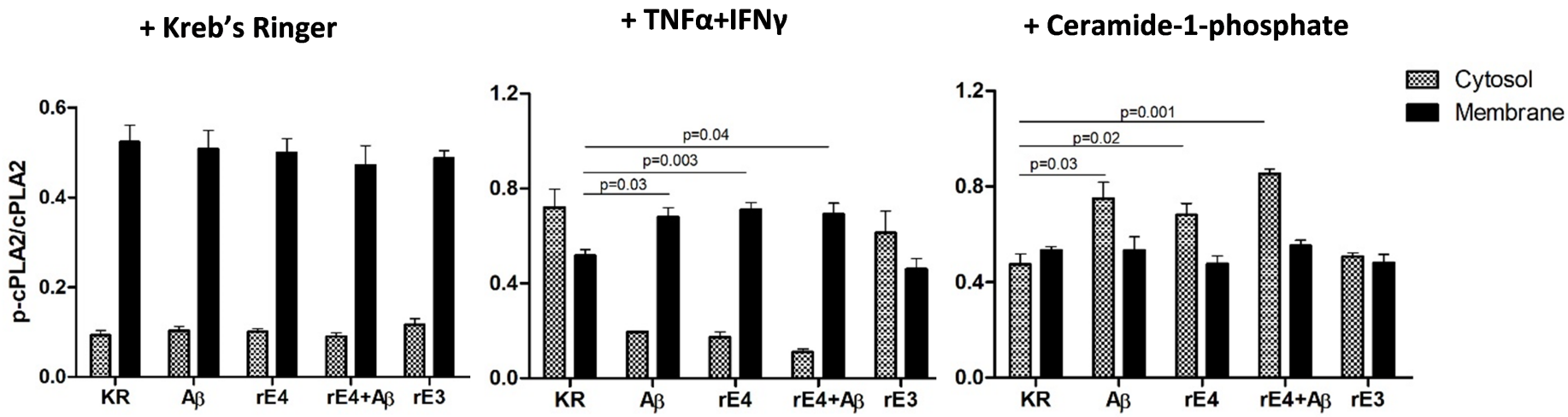

Figure 9

ApoE4 and AB42 induced cPLA2 activation in human postmortem frontal cortical synaptosomes. A, Synaptosomes were incubated in oxygenated Kreb's Ringer with different reagents: rApoE3, rApE4, AB42, A $42 /$ rApoE4 for 30 min, followed by 15 minutes incubation with Kreb's-Ringer (control), TNFa/IFNy or ceramide-1-phosphate, respectively. The synaptosomes were harvested and homogenized, and the membrane and cytosolic fractions of synaptosomes were isolated by centrifugation. CPLA2 was enriched in both fractions by immunoprecipitation with anti-cPLA2 antibodies, and the phosphorylated and total cPLA2 were detected by western blot. B-D, Densitometric quantification of blotting shown in A. 


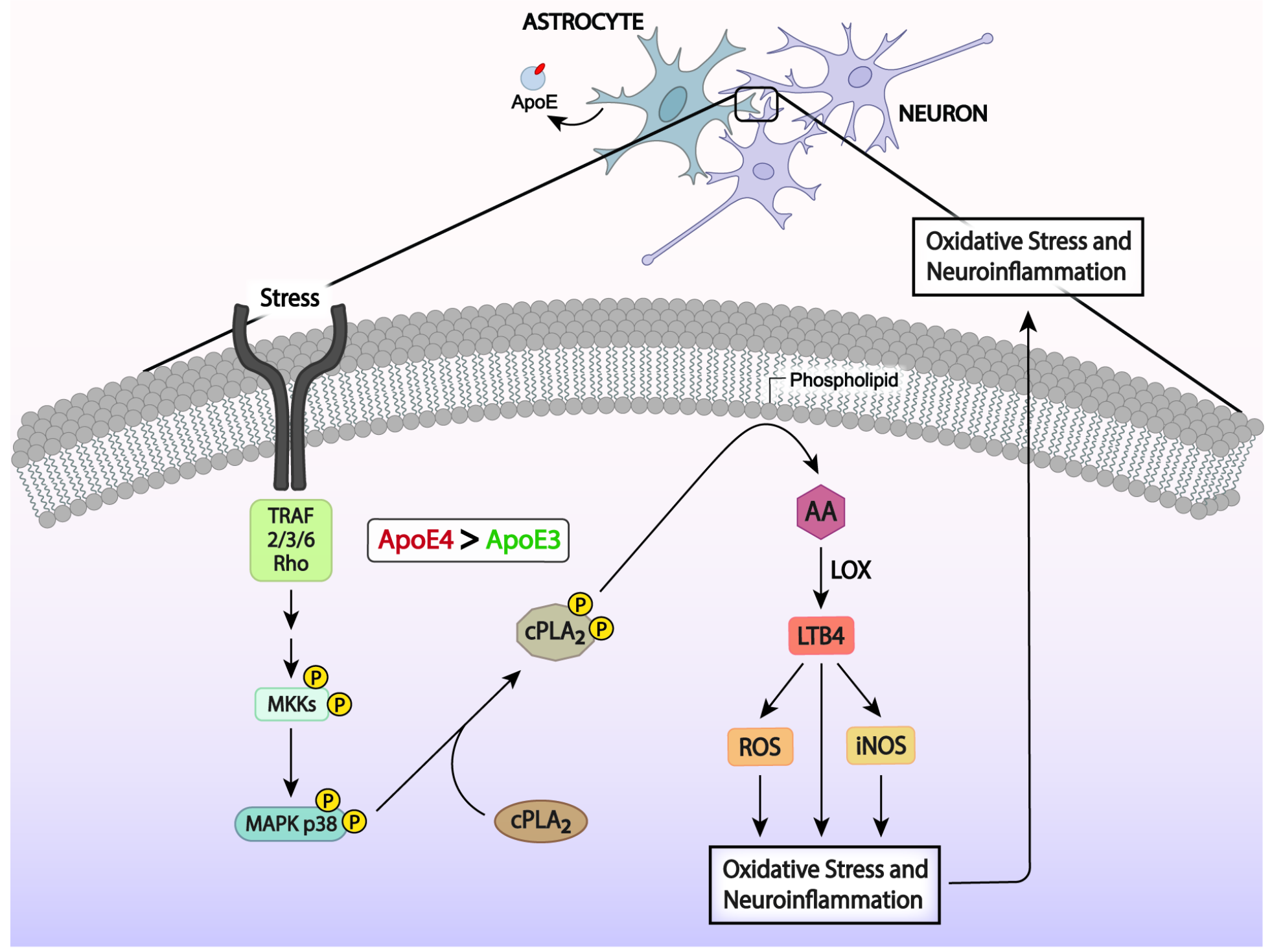

Figure 10

Illustration of ApoE4 in astrocytes and neurons inducing greater cPLA2 activation than ApoE3 through p38 MAPK pathway, leading to more LTB4, iNOS, and ROS production, increased oxidative stress and neuroinflammation.

\section{Supplementary Files}

This is a list of supplementary files associated with this preprint. Click to download.

- FigureS12.tif

- Figures2.tif

- FigureS3.tif

- FigureS4.tif

- FigureS5.tif 
- Tables1.docx

Page 35/35 